\title{
Investigation of the effect of forming parameters in incremental sheet forming using a micromechanics based damage model
}

\author{
Shakir Gatea ${ }^{1,2} \cdot$ Bin $\mathrm{Lu}^{3} \cdot$ Jun $\mathrm{Chen}^{3} \cdot \mathrm{Hengan}^{\mathrm{Ou}}{ }^{1} \cdot \mathrm{Graham} \mathrm{McCartney}^{1}$
}

Received: 17 March 2018 / Accepted: 20 July 2018 / Published online: 30 July 2018

(C) The Author(s) 2018

\begin{abstract}
The incremental sheet forming (ISF) process is considered as a feasible solution for forming a variety of small batch and even customised sheet components. The quality of an ISF product is affected by various process parameters, e.g. sheet material, stepdown, feed rate, tool diameter and lubricant. To produce an ISF part of sufficient quality and accuracy without defects, optimal parameters of the ISF process should be selected. In the present work, experiments and FE analyses were conducted to evaluate the influence of the main ISF process parameters including the step-down, feed rate and tool diameter on the formability and fracture of two types of pure Ti (grade 1 and 2). The Gurson-Tvergaard-Needleman (GTN) damage constitutive model with consideration of stress triaxiality was developed to predict ductile fracture in the ISF process due to void nucleation, growth and coalescence. It was found that the ISF parameters have varying degrees of effect on the formability and fracture occurrence of the two types of pure $\mathrm{Ti}$, and grade 2 pure $\mathrm{Ti}$ sheet is more sensitive than grade $1 \mathrm{Ti}$ sheet to the forming parameters due to low ductility.
\end{abstract}

Keywords ISF $\cdot$ Forming parameters $\cdot$ Formability $\cdot$ Fracture $\cdot$ Stress triaxiality GTN model

\section{Introduction}

Incremental sheet forming (ISF), also often named single point incremental forming (SPIF), is considered as an innovative technology as compared to traditional sheet metal forming processes due to the fact that traditional sheet metal forming processes involve additional costs linked to the equipment and tooling to be employed and the set-up time. ISF is a flexible process and the part can be plastically deformed by moving a hemispherical tool along a programmed path. In the ISF process, one important requirement is to obtain parts of the

Shakir Gatea

Shakir.Gatea@uokufa.edu.iq

Hengan Ou

H.Ou@nottingham.ac.uk

1 Department of Mechanical, Materials and Manufacturing Engineering, Faculty of Engineering, University of Nottingham, Nottingham NG7 2RD, UK

2 Department of Materials Engineering, Faculty of Engineering, University of Kufa, Kufa, Najaf, Iraq

3 Department of Plasticity Technology, Shanghai JiaoTong University, Shanghai 200030, China desired quality without fracture. To achieve this target, the ISF process parameters such as the step-down, tool diameter and feed rate should be adjusted before beginning the ISF process as inappropriate selection of these parameters will accelerate the fracture and influence the part's accuracy [1].

Many studies have been performed to evaluate the optimal parameters of the ISF process. Uniform plastic strain and thickness distribution can be obtained by reducing the stepdown and increasing the tool diameter and wall angle [2]. When the conventional tool path (constant step depth) is used, minimum thickness was noted which was closely related to the tool diameter, and its location was largely determined by the incremental depth $(\Delta Z)[3]$. The stresses in the contact region between the tool and the sheet and in the wall of the ISF part can be reduced by decreasing the step-down [4]. Through an experimental investigation to measure the forming force in ISF, [5] showed that the step-down has little effect on the formability of the ISF process. Two experimental designs were carried out to demonstrate the effect of ISF parameters. The first design showed that the step-down had an effect on the ISF formability and that the likelihood of the part to deform was enhanced by decreasing the step-down. In the second experiment, the results showed a small effect of stepdown on the maximum wall angle [6]. Many investigations 
Fig. 1 True strain-true stress curve of grade 1 and 2 pure titanium with different strain rates

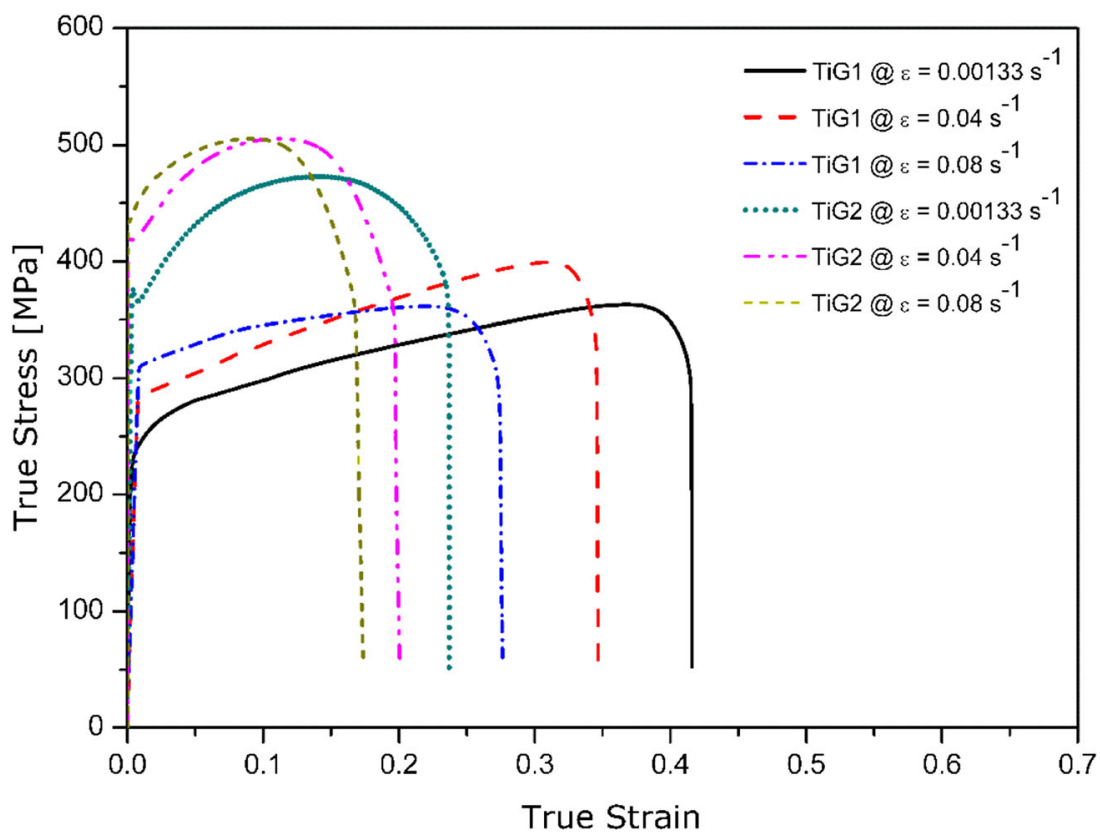

have proved that an increased step-down has a detrimental effect on the ISF formability [7-10].

High ISF formability can be achieved when a smaller tool diameter is used rather than a large tool diameter $[6,7,11]$. This is because with a small tool diameter, a highly concentrated zone of deformation is generated with a high strain which leads to enhanced formability. On the other hand, a bigger contact zone created by a large tool diameter leads to an increased forming force and reduced formability. The maximum value of the principal strain and sheet thinning were noted across the tool's trajectory on the circumference with the biggest tool diameter [12]. The major strain at fracture in ISF was located above the Nakajima's Fracture forming line (FFL) when lower tool diameter is used [13]. The effect of feed rate is considered insignificant as compared to the effect of tool diameter and step-down [7]. Furthermore, the feed rate has less effect on formability than the tool's rotational speed [14]. However, the formability of ISF can be altered by changing the feed rate. For example improved formability of the ISF part can be achieved using low feed rate $[6,15]$.

Small value of tool diameter to step-down ratio $(T / \Delta Z)$ is important to achieve satisfactory surface finish of commercially pure titanium (CP Ti) in SPIF [16]. In addition, the formability of CP Ti was enhanced by decreasing the tool diameter, step-down and feed rate [17]. The step-down value can change the surface roughness of ISF part, i.e. good surface finish is obtained with small values of step-down $[18,19]$. An experimental investigation was carried out by Bhattacharya et al. [7] to measure the effect of the step-down on the surface equality of Al5052 sheet. It was observed from the results the surface roughness decreases with increasing step-down up to a certain angle then increases. In addition, the surface finish decreases with increased tool diameter. Another investigation proved that the equality of formed part (Ti-6Al-4 V sheet) is influenced by the surface roughness of the tool and the friction between the sheet and tool but not by the tool radius [20]. Rough surface of ISF part could be obtained with low feed rate $(1200 \mathrm{~mm} / \mathrm{min})$ as compared to that obtained with higher feed rate $(8400 \mathrm{~mm} / \mathrm{min})$ [21].

It appears from the literature that there is a lack of detailed understanding and even opposing views on the effect of ISF process parameters, such as the step-down and feed rate on fracture occurrence in ISF. It also appears that most attention has been paid to studying the effect of ISF parameters using FE simulation without consideration of ductile fracture criteria. This work aims to provide a better understanding of the effect of three key forming parameters, namely the step down, feed rate and tool diameter, and their interactions on the formability and fracture in the ISF process of pure Ti grade 1 and 2. Experimental testing and FE analysis incorporating the ductile fracture criteria were used in order to evaluate the significance of each parameter and to examine the degree of
Table 1 Mechanical properties of pure titanium grade 1 and 2 at strain rate $0.00133 \mathrm{~s}^{-1}$

\begin{tabular}{llllll}
\hline Material & $\begin{array}{l}\text { Yield stress } \\
(\mathrm{MPa})\end{array}$ & $\begin{array}{l}\text { Ultimate tensile stress } \\
(\mathrm{MPa})\end{array}$ & $\begin{array}{l}\text { Young's modulus } \\
(\mathrm{GPa})\end{array}$ & $\begin{array}{l}\text { Poisson's } \\
\text { ratio }\end{array}$ & $\begin{array}{l}\text { Density }(\mathrm{Kg} / \\
\left.\mathrm{m}^{\wedge} 3\right)\end{array}$ \\
\hline Ti G1 & 223.49 & 363 & 108 & 0.34 & 4505 \\
Ti G2 & 367 & 473 & 105 & 0.34 & 4505 \\
\hline
\end{tabular}


Table 2 Effect of strain rate on fracture strain of pure titanium grade 1 and 2

\begin{tabular}{lll}
\hline Strain rate $\left[\mathrm{s}^{-1}\right]$ & \multicolumn{2}{l}{ Stain at fracture } \\
\cline { 2 - 3 } & Pure Ti grade 1 & Pure Ti grade 2 \\
\hline 0.00133 & 0.415 & 0.237 \\
0.04 & 0.346 & 0.2 \\
0.08 & 0.276 & 0.173 \\
\hline
\end{tabular}

its effect on formability and fracture occurrence. In addition, the sensitivity of material type to forming parameters is discussed in this work.

\section{Modelling of ductile fracture in ISF}

Understanding the deformation and fracture mechanism in ISF is very important as it can help to extend the capability of ISF to manufacture small batch or customised parts for different applications. Extensive research has been carried out to explain the deformation and fracture mechanism in ISF through theoretical analysis and experimental testing [22-29]. The results of these studies showed that the deformation and fracture in ISF part occur due to different mechanisms i.e. tensile meridional stress, through thickness shearing and bending.

It is well known that ductile fracture occurs due to microvoid nucleation, growth and coalescence mechanisms; in order to describe these mechanisms in analytical form in order to accurately predict fracture, several analytical models were

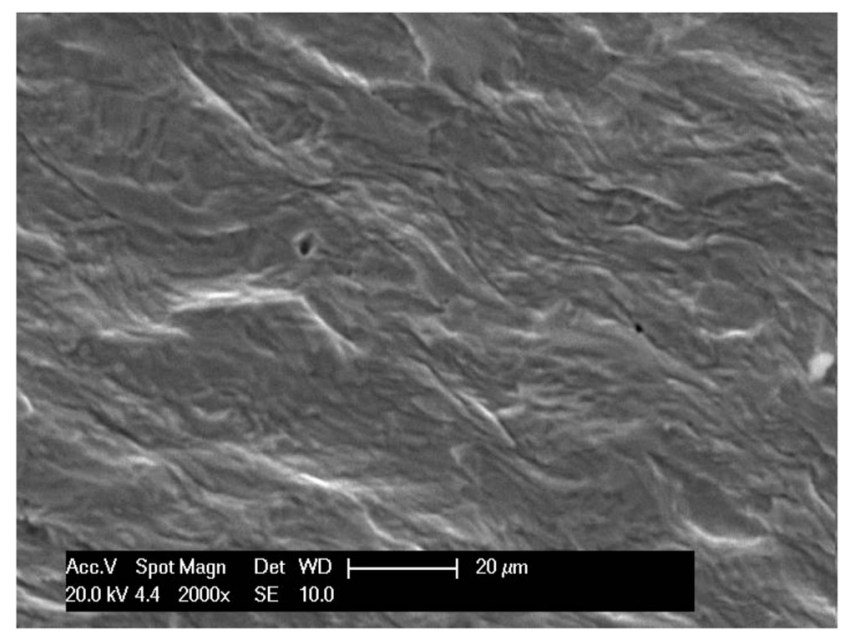

Fig. 3 Microstructure of pure Ti grade 2 before deformation

developed in the literature. However, the most popular model is Gurson's model [30], which was modified by Tvergaard and Needleman [31] (the Gurson-Tvergaard-Needleman (GTN) model) to incorporate additional parameters e.g. $q_{1}, q_{2}$ and $q_{3}=q_{1}^{2}$. A detailed description of modified GTN model can be found in $[24,32]$. A brief overview of the constitutive equation of GTN damage model is provided in this section In order to maintain consistency. The modified yield surface is defined as:

$\varnothing=\left(\frac{\sigma_{q}}{\sigma_{y}}\right)^{2}+2 q_{1} f^{*} \cosh \left(-\frac{3 q_{2} p}{2 \sigma_{y}}\right)-\left(1+q_{3} f^{* 2}\right)=0$

where $\mathrm{q} 1, \mathrm{q} 2$ and $\mathrm{q} 3$ are the constitutive parameters proposed by Tvergaard [33]; $\sigma_{q}=\sqrt{\frac{3}{2} S_{i j} S_{i j}}$ is equivalent to von Mises stress, with $\mathrm{S}$ representing the deviatoric part of the stress
Fig. 2 Load-displacement curve of pure Ti grade 1 and 2 shows the stages of determination of the GTN model parameters

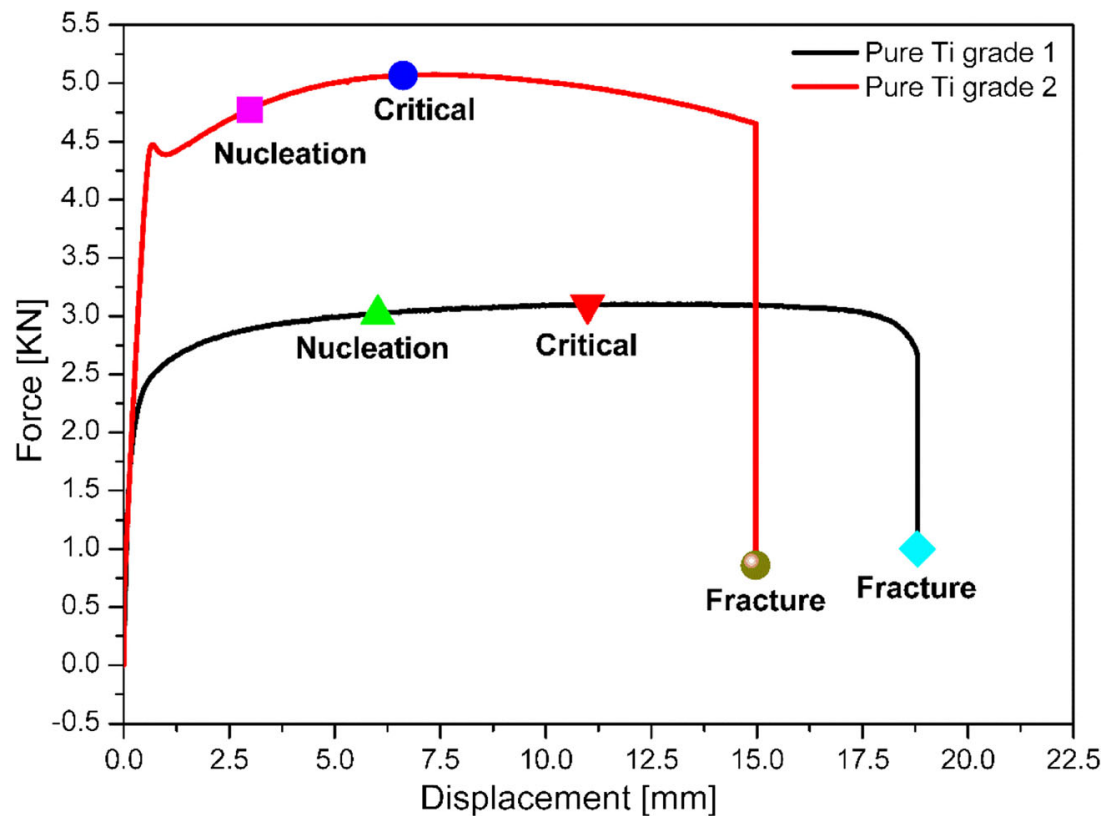


Fig. 4 Determination of void volume fraction at nucleation: a Microstructure of pure Ti grade 2 shows the voids nucleation and (b) strain distribution from digital image correlation at nucleation

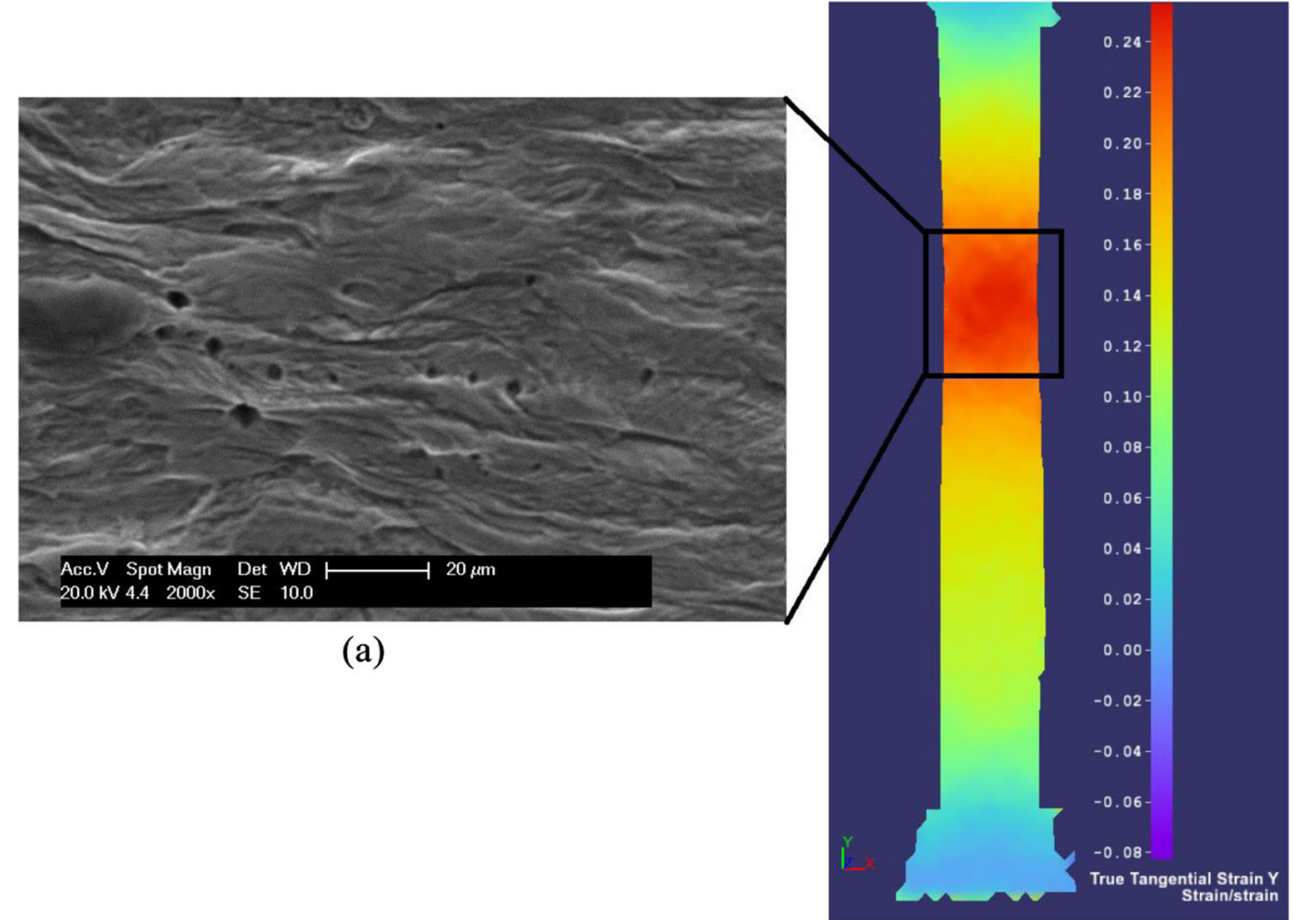

(b)

tensor; $p=-\frac{1}{3} \sigma_{i i}$ is the hydrostatic stress; and $\sigma_{\mathrm{y}}$ is the flow stress of the undamaged material matrix. The parameter $f^{*}$ was introduced by Tvergaard-Needleman to account for the final material failure for void coalescence. This parameter is a function of the void volume fraction $f$ and is specified as

$$
f^{*}=\left\{\begin{array}{cc}
f & \text { if } f \leq f_{c} \\
f_{c}+\frac{\bar{f}_{F}-f_{c}}{f_{f-f_{c}}}\left(f-f_{c}\right) & \text { if } f_{c}<f<f_{F} \\
\bar{f}_{F} & \text { if } f \geq f_{F}
\end{array}\right.
$$

Fig. 5 Determination of critical void volume: a Microstructure of pure Ti grade 2 shows the voids at critical stage and (b) strain distribution from digital image correlation at necking

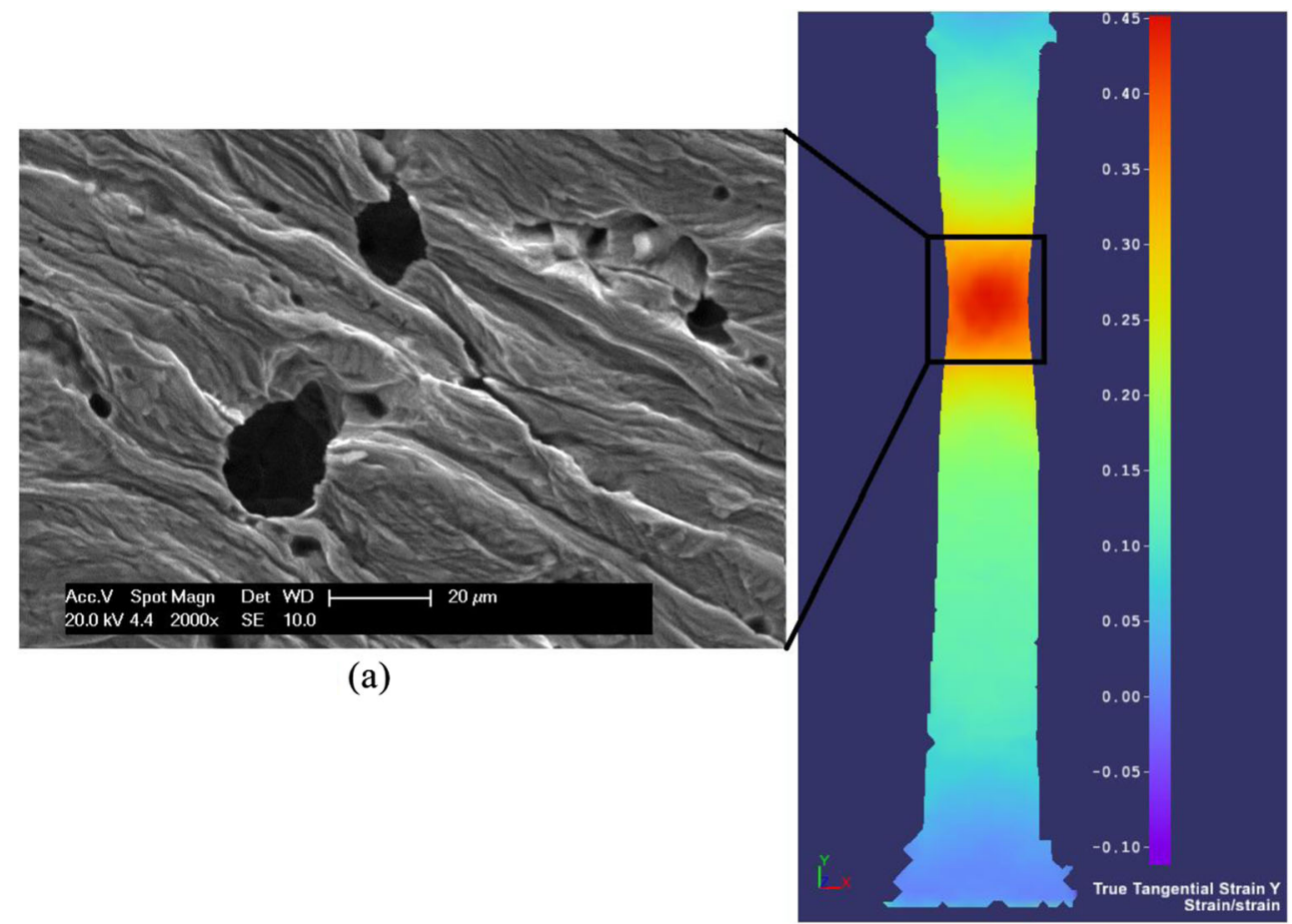

(b) 
Fig. 6 Determination of void volume fraction at fracture: a Microstructure of pure Ti grade 2 shows the voids at fracture and (b) strain distribution from digital image correlation at fracture

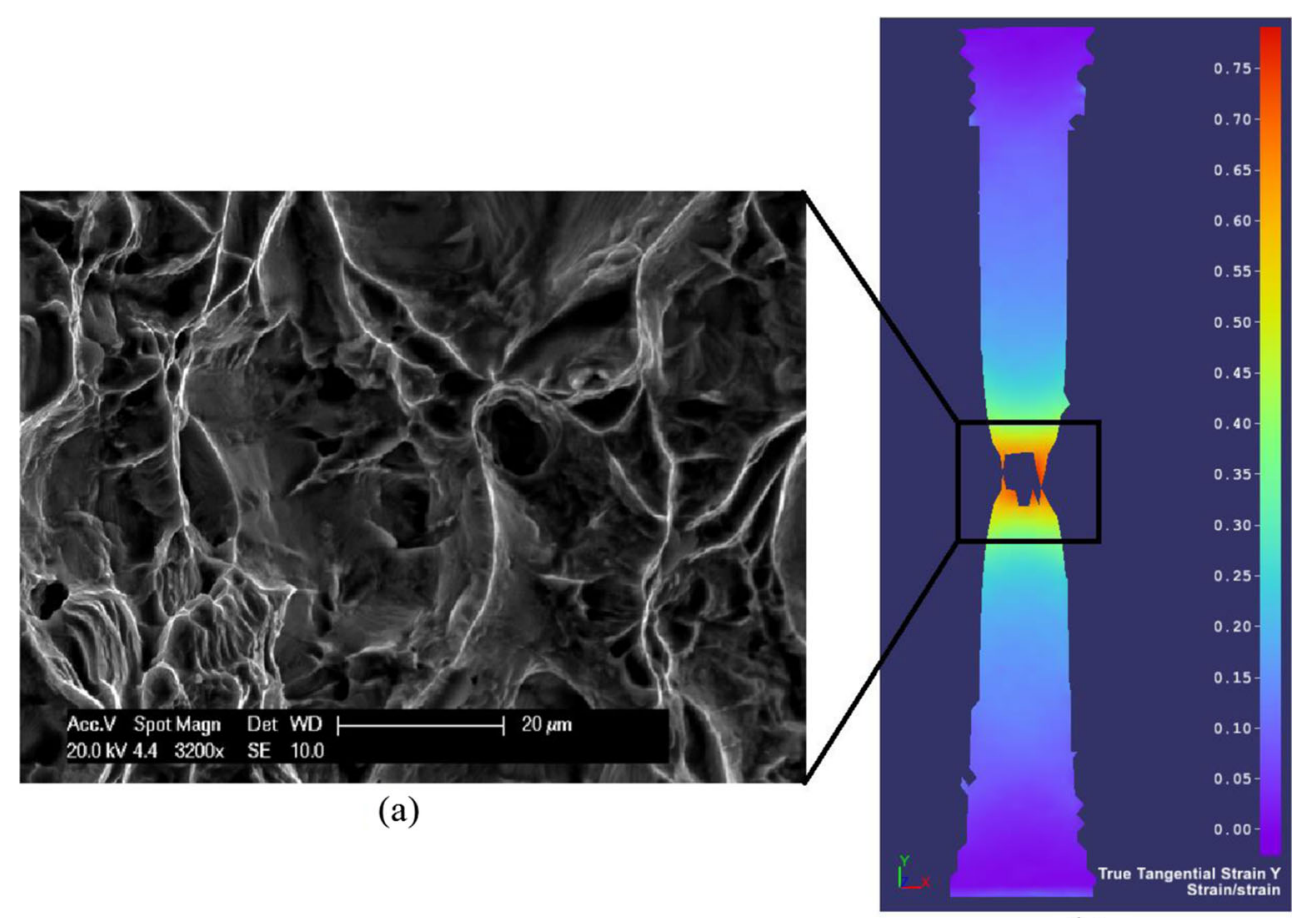

(b) where $f_{c}$ is the critical value of the void volume fraction, and $f_{F}$ is the fracture value of the void volume fraction when the material has completely lost its stress carrying capacity. The function of $\bar{f}_{F}$ is defined as

$\bar{f}_{F}=\frac{q_{1}+\sqrt{q_{1}^{2}-q_{3}}}{q_{3}}$

In the GTN model, the initial void volume fraction increases due to the nucleation of new micro-voids (Eq.4) and the growth of the old voids (Eq.6) and this model can be used to predict the fracture under a high triaxiality ratio (n). The GTN model was modified by Nahshon and Hutchinson [34] by adding an extension, as defined in Eq.7, to predict the fracture at zero stress triaxiality (shear state) or even negative stress triaxiality. Therefore, in the shear modified GTN model, the increment in the initial void volume fraction is determined based on the micro-voids' nucleation, growth and shear mechanisms.

$d f_{\text {nucleation }}=A d \bar{\varepsilon}_{m}^{p}$

where

$A=\left[\begin{array}{cc}\frac{f_{N}}{S_{N} \sqrt{2 \pi}} e^{-0.5\left(\frac{d \frac{p}{\bar{\varepsilon}_{m}-\varepsilon_{N}}}{S_{N}}\right)^{2}} & \text { if } p \geq 0 \\ 0 & \text { if } p<0\end{array}\right.$

where $d \bar{\varepsilon}_{m}^{p}$ is the increment of equivalent plastic strain, $\varepsilon_{m}^{p}$ is the total equivalent plastic strain, $f_{N}$ is the void volume fraction of the nucleated void; $\varepsilon_{N}$ is the mean value of the normal distribution of the nucleation strain; and $S_{N}$ is the standard deviation.

$d f_{\text {growth }}=(1-f) d \varepsilon_{i i}^{p}$

where $d \varepsilon_{i i}^{p}$ is the trace of the plastic strain tensor.

$d f_{\text {shear }}=k_{w} \frac{f \omega(\sigma)}{\sigma_{q}} S: \dot{\varepsilon}^{p}$

where $\omega(\sigma)$ is a function of the stress state and its value is determined as:

$\omega(\sigma)=1-\left(\frac{27 J_{3}}{2 \sigma_{q}^{3}}\right)^{2}$

The range of $\omega$ is between $0 \leq \omega \leq 1$ with all axisymmetric stress states $\omega=0$ and for all the states of pure shear plus a hydrostatic contribution $\omega=1 . k_{w}$ is a parameter producing the damage rate in shear loading, and $J_{3}$ is the third invariant of the deviatoric stress tensor $J_{3}=$ $\operatorname{det}(S)$.

Table 3 GTN damage model parameters of grade 1 and 2 pure titanium

\begin{tabular}{lllllllll}
\hline material & $f_{o}$ & $q_{1}$ & $q_{2}$ & $f_{N}$ & $\varepsilon_{N}$ & $S_{N}$ & $f_{c}$ & $f_{f}$ \\
\hline Ti G1 & 0.00138 & 1.5 & 1 & 0.017 & 0.3 & 0.1 & 0.2593 & 0.3025 \\
Ti G2 & 0.0052 & 1.5 & 1 & 0.018 & 0.3 & 0.1 & 0.07853 & 0.11648 \\
\hline
\end{tabular}




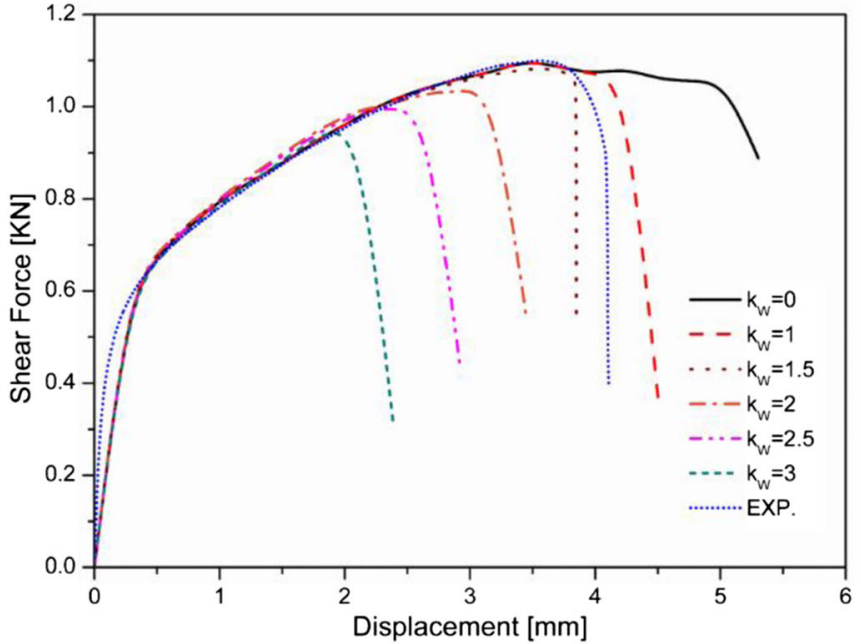

(a)

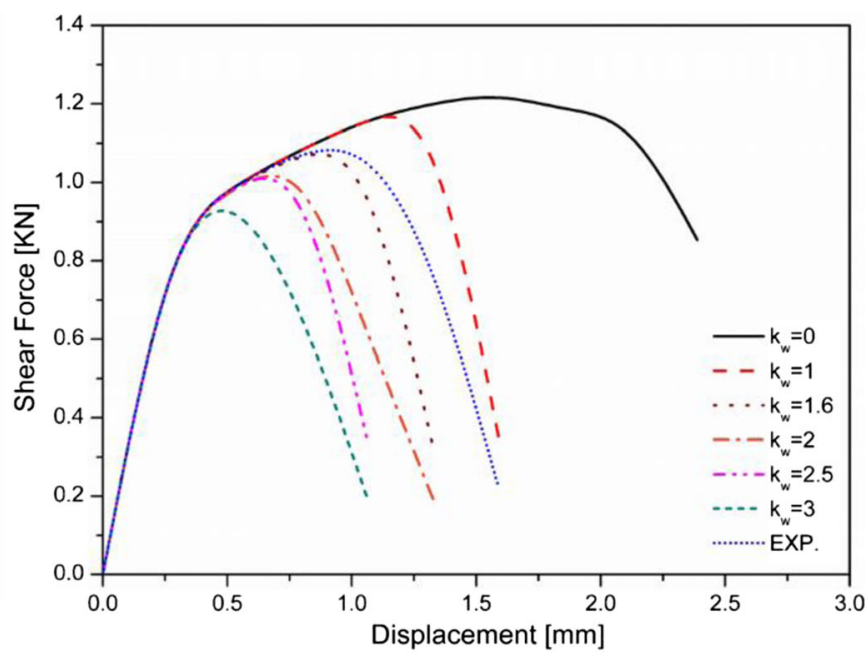

(b)

Fig. 7 Load-displacement curves with different $\mathrm{k}_{\mathrm{w}}$ parameter in comparison with Experimental data: a grade 1 pure Ti and (b) grade 2 pure Ti

The original GTN model works in the range of high stress triaxiality while the shear modified GTN model can predict the fracture under low stress triaxiality. Therefore, Nielsen and Tvergaard [35] developed the shear extension of Nahshon and Hutchinson to consider the effect of stress triaxiality [32], as defined in Eq.9:

$\omega_{o}=\omega(\sigma) \Omega(\eta)$, with $\Omega(\eta)=\left[\begin{array}{cc}1, & \text { for } \eta<\eta_{1} \\ \frac{\eta-\eta_{2}}{\eta_{1}-\eta_{2}}, & \text { for } \eta_{1} \leq \eta \leq \eta_{2} \\ 0, & \text { for } \eta>\eta_{2}\end{array}\right.$

where $\omega(\sigma)$ is given by Eq. $8, \eta_{1}<\eta_{2}$.

With this addition, the stress triaxiality modified GTN model can work in the same way as the original GTN model if $\eta>\eta_{2}$, and as the shear modified GTN model if $\eta<\eta_{1}$.

In this study, the GTN model which considers the effect of stress triaxiality is used to investigate the effect of ISF process parameters including the step-down, feed rate and tool diameter, on the deformation and fracture mechanism due to it was proved this model can predict fracture under different stress triaxiality conditions.

\section{Experimental testing}

\section{Materials characterizations}

To determine the material properties of pure titanium grade 1 and 2, specimens were machined and tested according to British standard specification (BS EN 10002-1). EDM was used to obtain the tensile specimen from $0.7 \mathrm{~mm}$ thick grade 1 pure titanium sheet and $0.8 \mathrm{~mm}$ thick grade 2 pure titanium sheets. The specimens were loaded until fracture occurred. The tensile test was carried out using an INSTRON 5581 testing machine. To predict the effect of feed rate on the formability and fracture of incremental sheet forming using FE analysis, tensile test of both types of pure Ti is performed at
Fig. 8 Geometric shape of hyperbolic cone: a CAD model and (b) cross-section profile

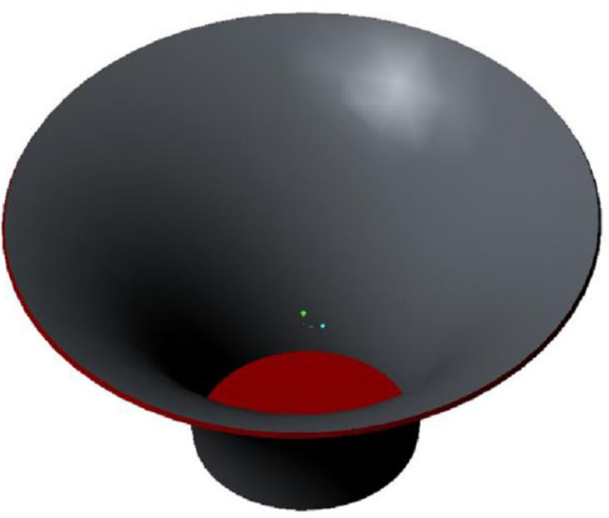

(a)

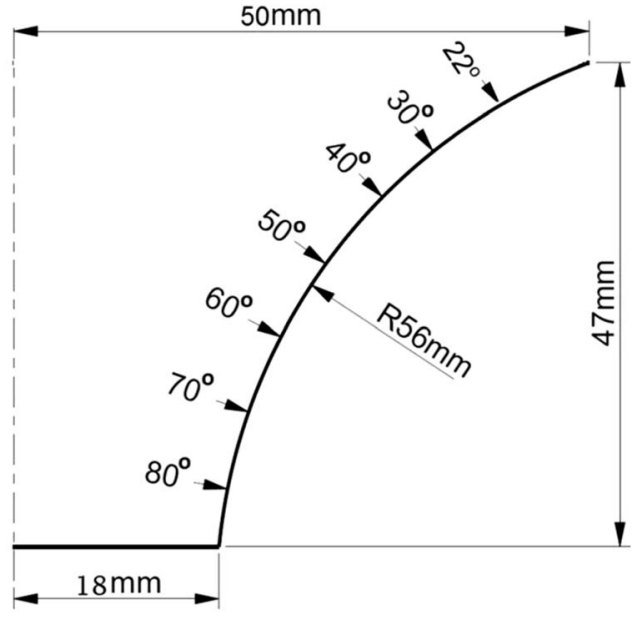

(b) 
Fig. 9 SPIF experiments of pure titanium sheet: a CNC milling machine and (b) the fixture that used to fix the sheet

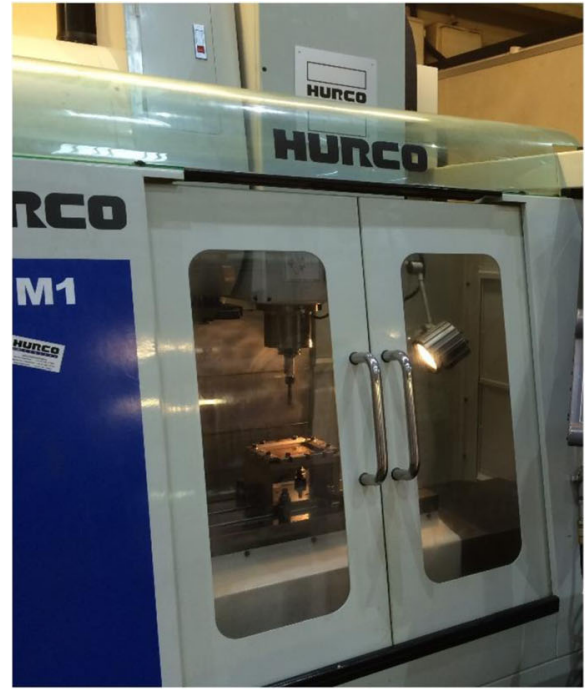

(a)

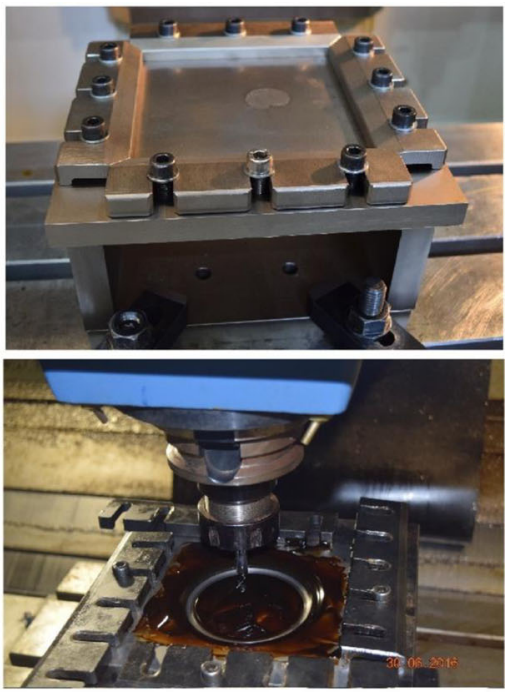

(b) three strain rates $\left(0.00133,0.04\right.$ and $\left.0.08 \mathrm{~s}^{-1}\right)$. Figure 1 shows the true stress-true strain curves of grade 1 and 2 pure Ti at different strain rates. Form the figure, it is observed that the ultimate tensile strength is increased and fracture elongation decreased with increased strain rate for both types of pure Ti. To measure the displacement on the surface of the specimens during the tensile tests, a Dantec Q-400 DIC (digital image correlation) system was used. The mechanical properties of the pure titanium grade 1 and 2 at strain rate $0.00133 \mathrm{~s}^{-1}$ are summarized in Table 1 . The effect of strain rate on the strain at fracture is reported in Table 2.

To determine the void volume fraction (VVF) values of grade 1 and 2 pure $\mathrm{Ti}$ at the initial and following stages of deformation, i.e. nucleation, critical and fracture, a tensile test was run with digital image correlation (DIC) for both materials. The DIC was used to determine the exact position of the maximum deformation region on the tensile specimen. Then this region was cut and scanned under a scanning electron microscope (SEM) to evaluate the nucleation and the growth of the voids in the Ti matrix. Figure 2 shows at which load and displacement stage that the nucleation begins and this is followed by the critical (the displacement at which material response shows softening behaviour in uniaxial tension) and fracture positions in the loaddisplacement curve for both grade 1 and 2 pure Ti specimens. The nucleation in the voids $\left(f_{N}\right)$ is started after the yield point and before the maximum stress (maximum load). Unfortunately, no threshold is given for nucleation. Therefore, the tensile test was stopped at different displacements in order to scan the sample under SEM to check whether nucleation had started. The critical value of VVF $\left(f_{c}\right)$ is determined when the tensile force reaches the maximum value and the necking is started in the samples. The fracture value of VVF $\left(f_{F}\right)$ is determined by scanning the fracture surface of tensile sample.

The SEM's images were analysed using ImageJ software to determine the quantitative values of VVF. Figures 3, 4, 5 and 6 explain the technique used to determine the VVF at different stages. The GTN model parameters for grade 1 and 2 pure Ti sheets are listed in Table 3.

The parameter producing the damage rate in shear loading $\left(\mathrm{k}_{\mathrm{w}}\right)$ is located between 1 and $3\left(1<\mathrm{k}_{\mathrm{w}}<3\right)$ for many alloys [34], and shear test is used to calibrate its value. In this study the shear specimen was design according to modified ASTM B831 shear test [36] and INSTRON 5581 testing machine was employed to carry out the test at cross head speed $(0.1 \mathrm{~mm} / \mathrm{s})$. In order to select the optimum value of $\mathrm{k}_{\mathrm{w}}$ parameter for both grades of pure $\mathrm{Ti}$, the value of $\mathrm{k}_{\mathrm{w}}$ was changed in the $\mathrm{FE}$ simulation to get the best fitting with experimental loaddisplacement curve of shear test. Figure 7 shows the comparison between load-displacement curves of experimental and simulation with different values of $\mathrm{k}_{\mathrm{w}}$ for both types of pure Ti. A good agreement between the experimental and FE simulation load-displacement curves is found when the $\mathrm{kw}$ values are 1.5 for grade 1 pure Ti and 1.6 for grade 2 pure Ti, respectively. Therefore, the $\mathrm{k}_{\mathrm{w}}$ with values of 1.5 and 1.6 were used in this investigation to produce the damage rate in shear loading for grade 1 and grade 2 pure Ti, respectively.

Table 4 ISF parameters

\begin{tabular}{llll}
\hline Factor & Level 1 & Level 2 & Level 3 \\
\hline Step-down $(\mathrm{mm})$ & 0.2 & 0.4 & 0.6 \\
tool diameter $(\mathrm{mm})$ & 8 & 10 & 15 \\
Feed rate $(\mathrm{mm} / \mathrm{min})$ & 1000 & 2000 & 3000 \\
\hline
\end{tabular}


Table 5 Design of Experiments

\begin{tabular}{llll}
\hline Experiment No. & Step-down $[\mathrm{mm}]$ & Feed rate $[\mathrm{mm} / \mathrm{min}]$ & Tool diameter $[\mathrm{mm}]$ \\
\hline 1 & 0.2 & 1000 & 10 \\
2 & 0.4 & 1000 & 10 \\
3 & 0.6 & 1000 & 10 \\
4 & 0.2 & 2000 & 10 \\
5 & 0.2 & 3000 & 10 \\
6 & 0.2 & 1000 & 8 \\
7 & 0.2 & 1000 & 15 \\
\hline
\end{tabular}

\section{Design of Experiments}

A HURCO CNC milling machine (VM10) was employed to carry out the SPIF tests at ambient temperature for a hyperbolic truncated cone shape with varying wall angles, as shown in Fig. 8. The sheet was fastened using a special fixture assembled on the CNC milling machine as shown in Fig. 9. The blank size is $140 \mathrm{~mm}$ X $140 \mathrm{~mm}$ with a sheet thickness of $0.7 \mathrm{~mm}$ for grade 1 pure Ti and 0.8 for grade 2 pure Ti. The tool path (G-code) was generated using a commercial CAD/CAM system. To evaluate the effect of ISF parameters on the formability and the fracture location of the grade 1 and 2 pure Ti hyperbolic truncated cone, three levels of values are employed as input for each parameter of ISF and their values are listed in Table 4. The SPIF experimental test was repeated three times to ensure repeatability of results and the average value is taken. The experimental ISF design is shown in Table 5; this design was used for both types of pure Ti.

The SPIF test also was carried out to deform a hyperbolic truncated pyramid with the same profile as the hyperbolic truncated cone (Fig. 8b) in order to use it with the hyperbolic truncated cone to construct the FFL; to study the effect of ISF parameters on the fracture strain level. Two points were recorded in the first quadrant of the forming limit diagram: one in the plane strain zone from the hyperbolic truncated cone and another one from the biaxial strain zone from the hyperbolic truncated pyramid. These two points were used to determine the slope of the FFL lines. The hyperbolic truncated pyramid ISF test was done with a step down equal to
$0.2 \mathrm{~mm}$ and tool diameter of $10 \mathrm{~mm}$. the feed rate was set to $1000 \mathrm{~mm} / \mathrm{min}$ with non-rotating tool.

The technique was used to construct the FFL of ISF experimentally consist of using a laser to print a grid of circles on the outer surface of the blank with a $2 \mathrm{~mm}$ initial diameter. These circles were changed to ellipses due to plastic deformation at the end of ISF testing. An optical microscope was employed to measure the minor axis dimension of the ellipses. The procedure used to construct the FFL began by determining the minor strain just outside the fracture region using plastic strain equation $\left(\varepsilon_{\text {minor }}=\ln \left(\frac{d}{d_{o}}\right)\right.$ ) based on the initial diameter $\left(d_{o}\right)$ of the printed circle and the finial length of the minor axis of the ellipse (d), then the specimen is cut to measure the thickness along the fracture in both sides to get the average value of the thickness strain. The major strain was determined using volume constancy based on the minor and the thickness strains. Figure 10 shows the deformed circles on the hyperbolic truncated cone and hyperbolic truncated pyramid of pure Ti grad 1.

\section{FEA model}

Abaqus/Explicit was used to establish the 3D FE model of ISF to study the effect of forming parameters on the formability and fracture in ISF. The truncated conical and pyramidal geometries with varying forming angles were taken as a benchmark in this work. The blank was modelled as a deformable
Fig. 10 The distortion grid on the deformed SPIF parts: a hyperbolic truncated cone shape and (b) hyperbolic truncated pyramid shape

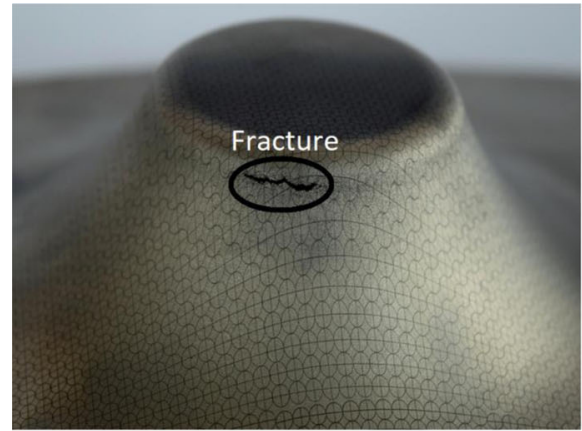

(a)

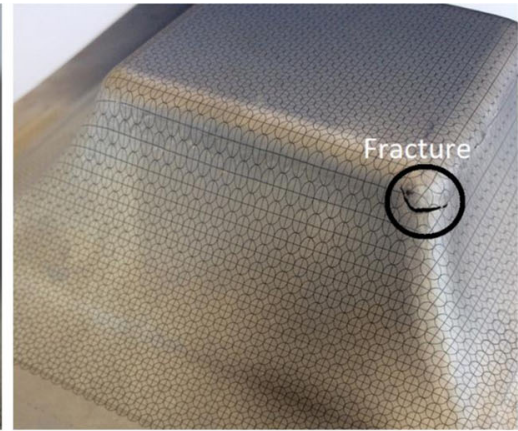

(b) 
Table 6 Effect of step-down on the formability and fracture of ISF grade 1 and 2 pure $\mathrm{Ti}$

\begin{tabular}{|c|c|c|c|c|c|c|c|c|}
\hline \multirow[t]{3}{*}{ Step- down $[\mathrm{mm}]$} & \multicolumn{4}{|c|}{ Pure Ti grade 1} & \multicolumn{4}{|c|}{ Pure Ti grade 2} \\
\hline & \multicolumn{2}{|c|}{ Fracture depth $[\mathrm{mm}]$} & \multicolumn{2}{|c|}{ Fracture angle $\left[{ }^{\circ}\right]$} & \multicolumn{2}{|c|}{ Fracture depth $[\mathrm{mm}]$} & \multicolumn{2}{|c|}{ Fracture angle $\left[{ }^{\circ}\right]$} \\
\hline & $\mathrm{FE}$ & EXP. & $\mathrm{FE}$ & EXP. & $\mathrm{FE}$ & EXP. & $\mathrm{FE}$ & EXP. \\
\hline 0.2 & 31 & 32.2 & 69.45 & 70.83 & 13 & 14.46 & 47.74 & 49.83 \\
\hline 0.4 & 30.5 & 32 & 68.91 & 70.62 & 11.7 & 12.9 & 45.92 & 46.26 \\
\hline 0.6 & 29.5 & 31.4 & 67.81 & 69.98 & 11.2 & 11.8 & 42.47 & 44.74 \\
\hline
\end{tabular}

body with 8-noded hexahedral elements and a reduced integration method (C3D8R). The material behaviour of sheet metal was assumed to be isotropic elastic and plastic yielding (von Mises isotropic yield function), and the forming tool, backing plate and blank holder were regarded as rigid surfaces. Coulomb's friction law was applied with a friction coefficient of 0.1 to model the contact between the forming tool and blank and of 0.2 between the blank and other parts including the backing plate and the holder. The stress triaxiality-modified GTN damage constitutive model was developed and implemented in Abaqus/Explicit via a VUMAT user subroutine to predict the fracture in the ISF process.
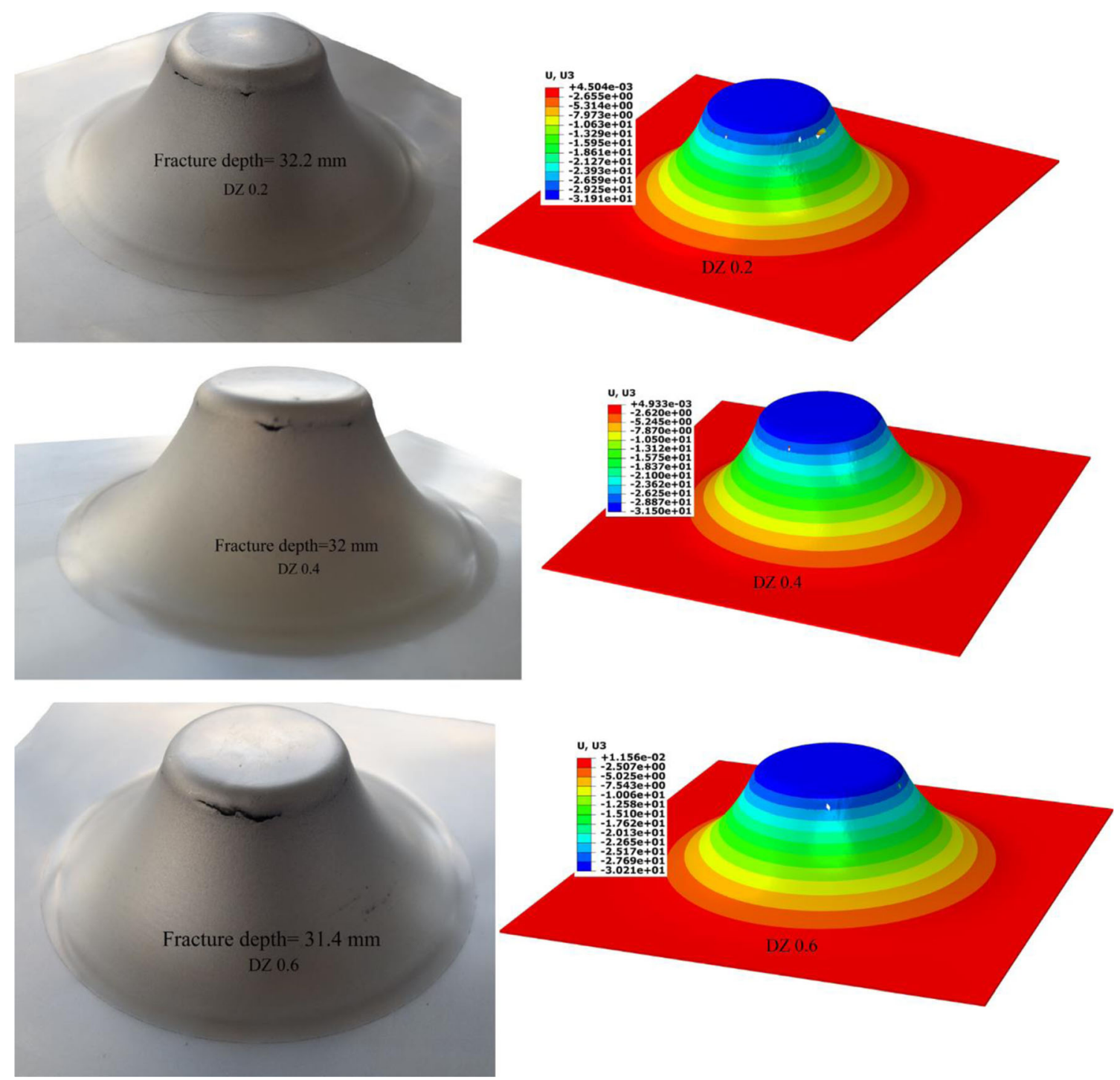

Fig. 11 Simulated results of fracture depth (Z-displacement) from the modified GTN model with stress triaxiality in comparison to the actual experiment of the pure Ti grade 1 hyperbolic cone shape with different steps-down 

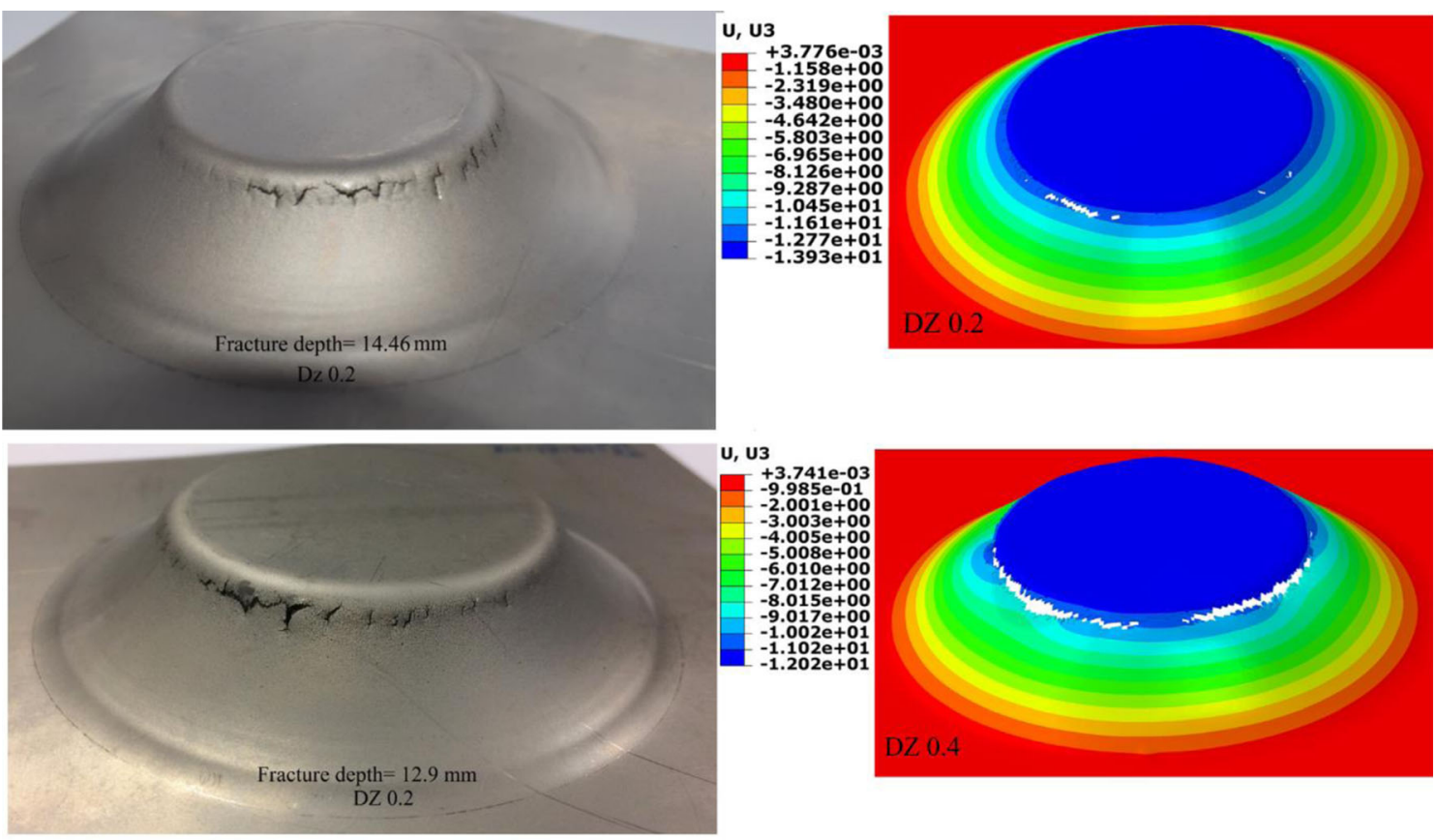

U, U3
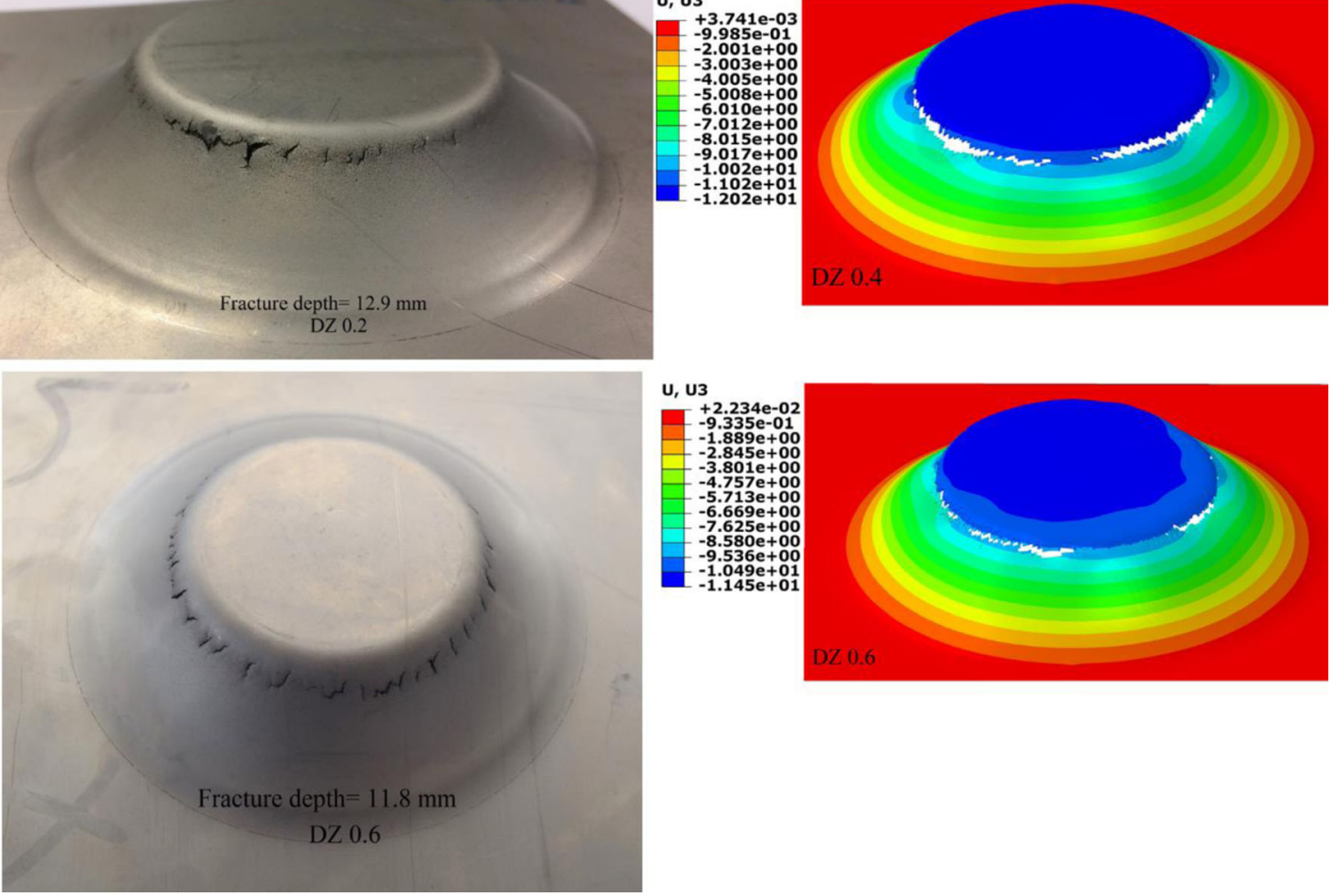

u, $\mathbf{u 3}$

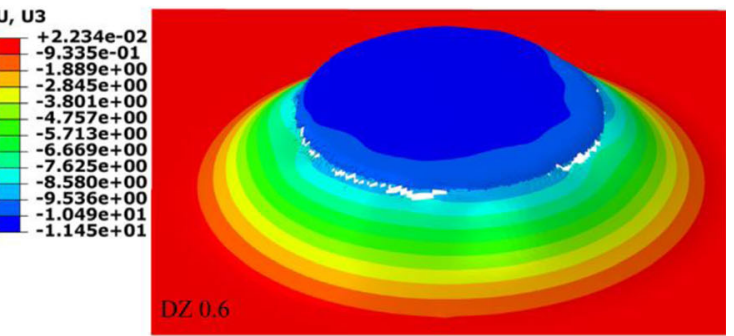

Fig. 12 Simulated results of fracture depth (Z-displacement) from the modified GTN model with stress triaxiality in comparison to the actual experiment of the pure Ti grade 2 hyperbolic cone shape with different steps-down

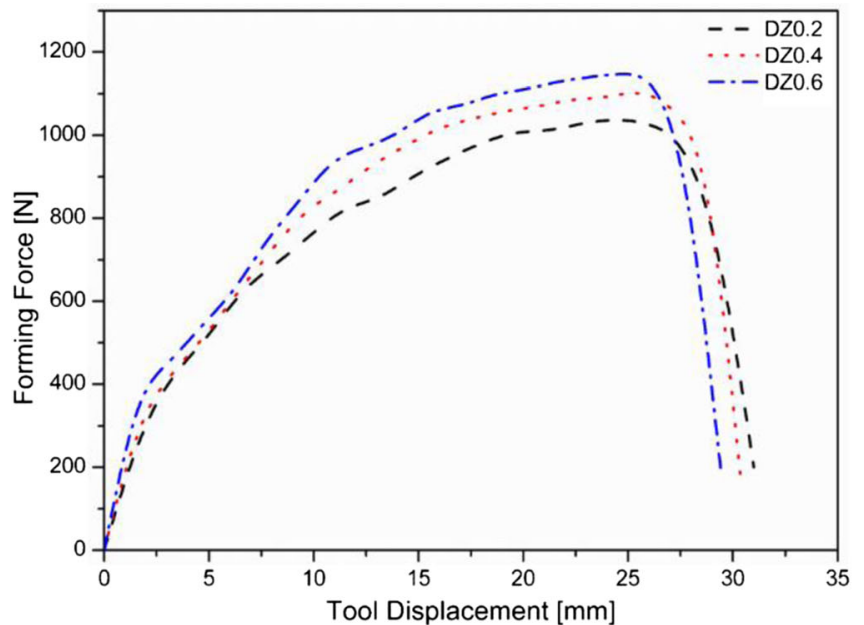

(a)

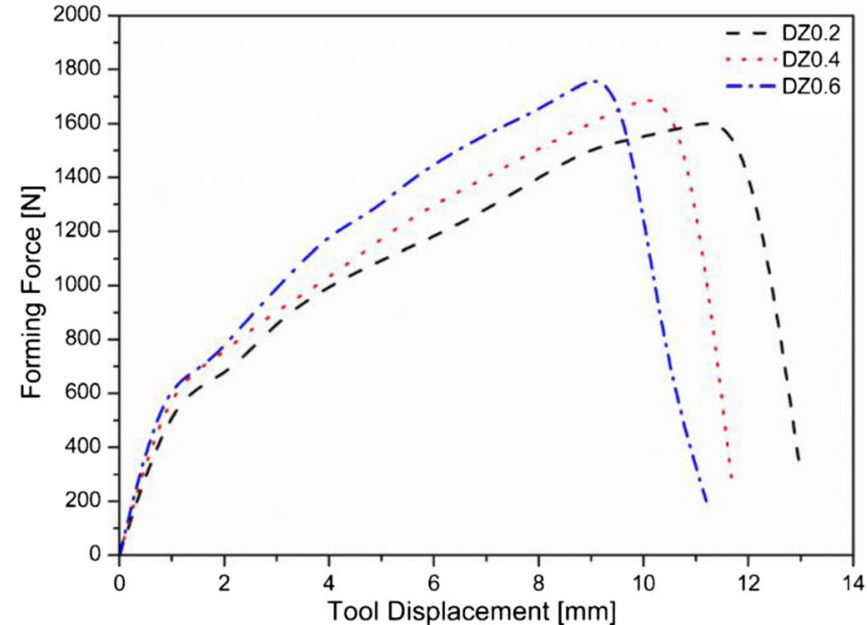

(b)

Fig. 13 Comparison of vertical forming load with different steps down (DZ): (a) pure Ti grade 1 and (b) pure Ti grade 2 


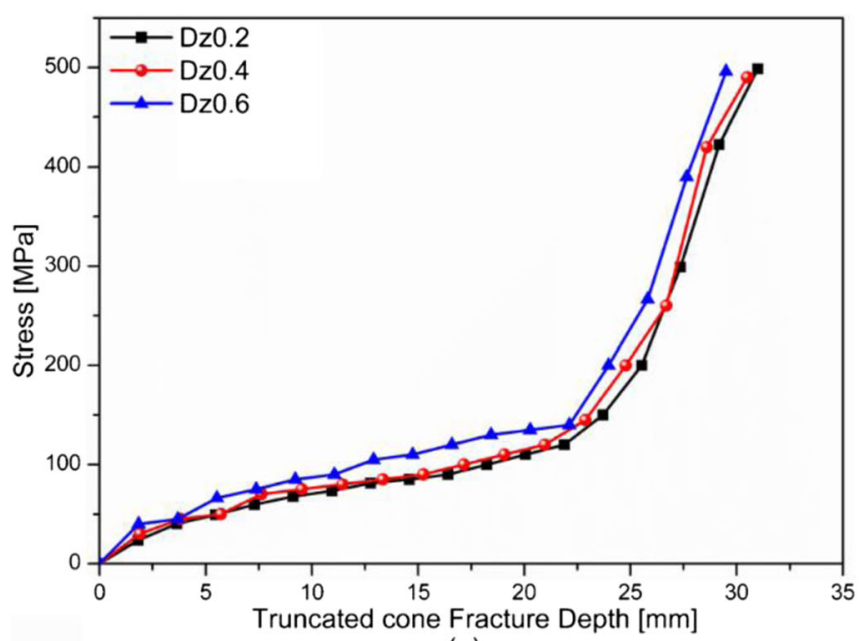

(a)

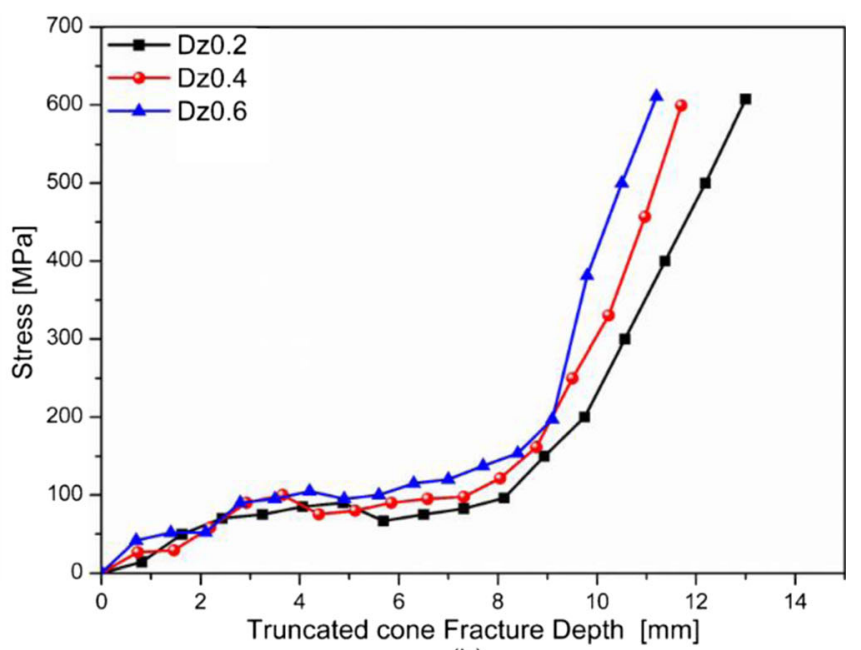

(b)

Fig. 14 Mises Stress distribution with different steps down (DZ): a pure Ti grade 1 and (b) pure Ti grade 2

Typical sheet materials developed by rolling process exhibit some degree of anisotropy. Abaqus supports more than one yield criterion, e.g. the Von-Mises and Hill yield criteria. The Mises yield criterion is used to define isotropic yielding, while the Hill yield criterion is utilized to define anisotropic yielding. In some studies, Hill'48-GTN yield criterion was developed to predict the fracture of anisotropic sheet [37, 38]. In this study, the strength-differential effects and anisotropy of the Ti materials are neglected.

Solution dependent variable can be defined in the GTN subroutine to indicate the element is to be removed from the calculations, with this variable the element removes based on a predetermined set of specification, e.g. if the void volume fraction in the element reaches to the critical value. In this study, the fracture is modelled using element deletion technique. When the accumulated value of the VVF in the FE model becomes equal or larger to the experimental value of VVF, the element in the FE model gets automatically deleted from the model.

\section{Results and discussion}

\section{Effect of step down}

The step-down was set to three values: $0.2,0.4$ and $0.6 \mathrm{~mm}$ (Experiment Nos. 1, 2 and 3, respectively). The experimental and $\mathrm{FE}$ values of the maximum wall angle (fracture angle) and the fracture depth of the hyperbolic truncated cone under different steps-down are listed in Table 6. It is clear from the table

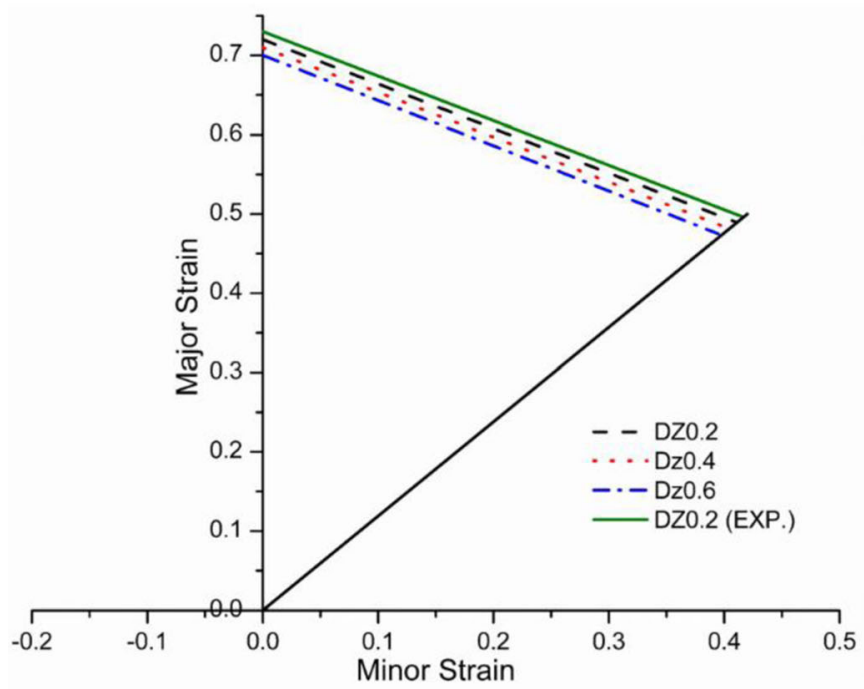

(a)

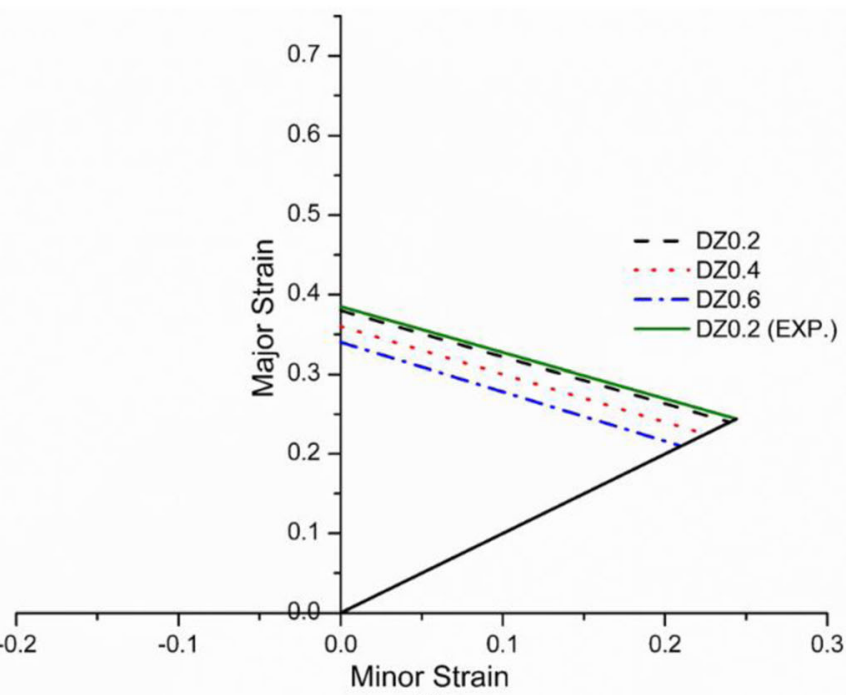

(b)

Fig. 15 FFLs with different steps down (DZ): a pure Ti grade 1 and (b) pure Ti grade 2 


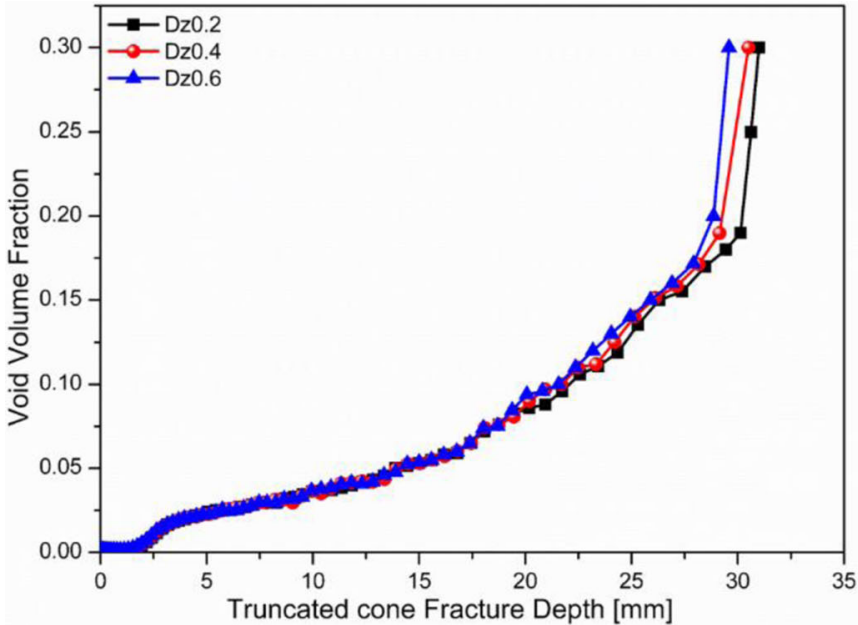

(a)

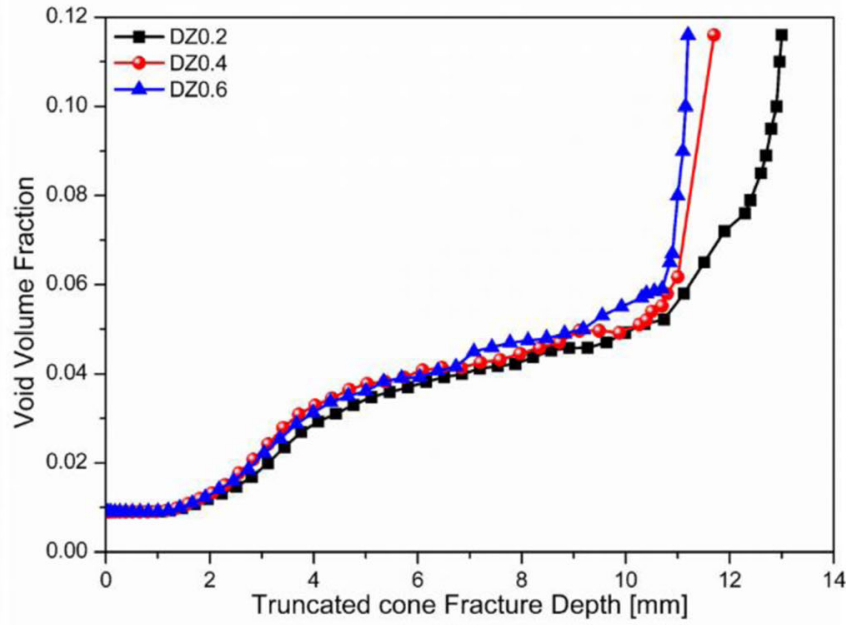

(b)

Fig. 16 Distribution of the void volume fraction obtained by numerical simulation of the ISF process with different steps-down (DZ): a pure Ti grade 1 and (b) pure Ti grade 2

that the influence of step-down on the formability (maximum wall angle) and fracture depth of grade 1 pure Ti is small as compared to that of grade 2 pure Ti. However, the experimental wall angle of grade 1 pure Ti hyperbolic truncated cone increases by $0.85^{\circ}$ when the step-down is changed from $0.6 \mathrm{~mm}$ to $0.2 \mathrm{~mm}$, while the increase in the wall angle of grade 2 pure Ti is about $5^{\circ}$.

To validate the capability of the GTN model with the consideration of stress triaxiality to predict the fracture depth accurately with different steps-down in the ISF process, the FE results were compared with those of the experimental test for grade 1 and 2 pure Ti, as shown in Table 6 and Figs. 11 and 12. From the table and the figures, it can be seen that there is a good correlation between the FEA of the stress triaxiality modified GTN model and the experimental data of the fracture depth and maximum wall angle.

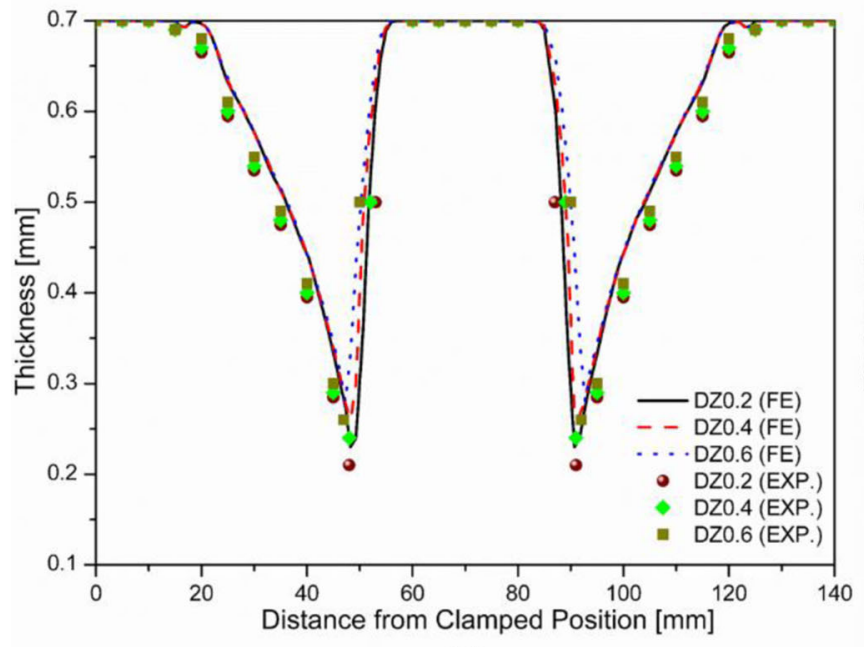

(a)
Figure 13 shows the variation of the vertical forming force with tool displacement using different steps-down for both grades of pure Ti. The figure reveals that the forming force increases with increased step-down; this is due to the fact that stretching in the wall of the ISF part increases with greater step-down and this also works to increase the stress distribution in the forming wall, as shown in Fig. 14, leading to early fracture in the deformed part.

As the step-down increases, the tensile stress in the forming wall increases and the level of fracture strain decreases, as shown in Fig. 15. It is noted from the figure that the values of major strain decrease with increased step-down for both types of pure $\mathrm{Ti}$, but the decrease percentage is higher with pure Ti grade 2 . The increase in the tensile stress due to greater step-down works to enhance the growth of the initial voids and the nucleation of new voids early and, when the void

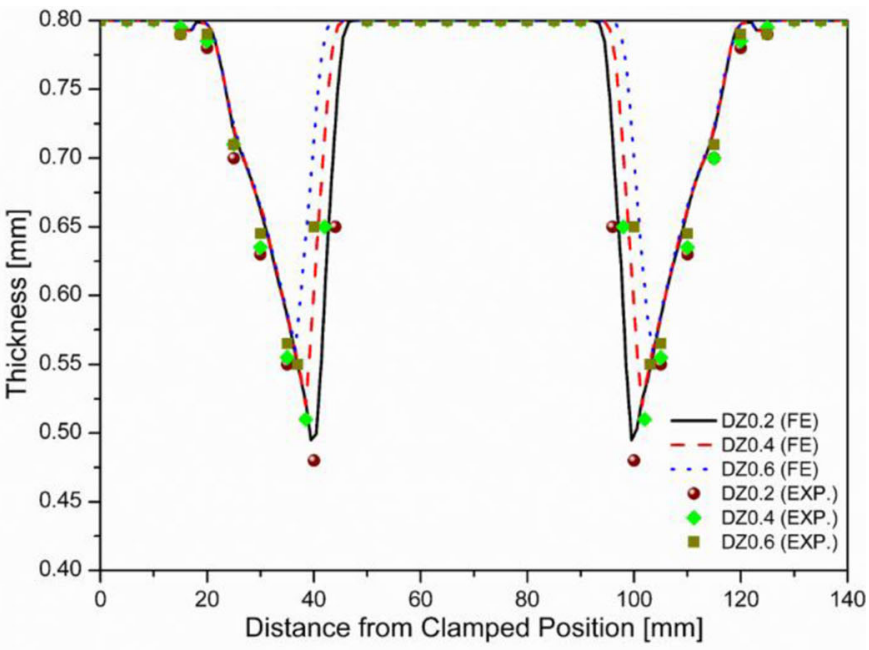

(b)

Fig. 17 Thickness distribution with different steps down (DZ): a pure Ti grade 1 and (b) pure Ti grade 2 
Table 7 Effect of feed rate on the formability and fracture of ISF grade 1 and 2 pure $\mathrm{Ti}$

\begin{tabular}{|c|c|c|c|c|c|c|c|c|}
\hline \multirow[t]{3}{*}{ Feed-rate $[\mathrm{mm} / \mathrm{min}]$} & \multicolumn{4}{|c|}{ Pure Ti grade 1} & \multicolumn{4}{|c|}{ Pure Ti grade 2} \\
\hline & \multicolumn{2}{|c|}{ Fracture depth [mm] } & \multicolumn{2}{|c|}{ Fracture angle $\left[{ }^{\circ}\right]$} & \multicolumn{2}{|c|}{ Fracture depth $[\mathrm{mm}]$} & \multicolumn{2}{|c|}{ Fracture angle $\left[{ }^{\circ}\right]$} \\
\hline & $\mathrm{FE}$ & EXP. & $\mathrm{FE}$ & EXP. & $\mathrm{FE}$ & EXP. & $\mathrm{FE}$ & EXP. \\
\hline 1000 & 31 & 32.2 & 69.45 & 70.83 & 13 & 14.46 & 47.74 & 49.83 \\
\hline 2000 & 29.8 & 30.9 & 68.14 & 69.42 & 11 & 11.5 & 43.73 & 45.73 \\
\hline 3000 & 28.7 & 29.7 & 66.92 & 68.1 & 9.9 & 10.5 & 41.95 & 43.74 \\
\hline
\end{tabular}

volume fraction reaches a certain value $(0.305$ in grade 1 pure Ti and 0.116 in grade 2 pure Ti), fracture occurs, as shown in Fig. 16. It is clear from the figure that there is a uniform growth of void volume fraction in the early stages of deformation with both grades of pure Ti until a certain depth; then, the void volume fraction curves begin to separate from each other with rapid growth, followed by a sudden fracture.

Figure 17 shows the effect of step-down on the hyperbolic truncated cone thickness distribution at fracture. It is evident that the thinning increases uniformly before reaching the maximum value (fracture thickness) in the transition region between the contact and non-contact zones. Also, it is clear that more thickness reduction can be achieved with a smaller stepdown as a larger wall angle can be achieved with a small stepdown.

In summary, it can be concluded that formability appears better with a small step-down than a large step -down with both types of pure Ti because the large step-down works to
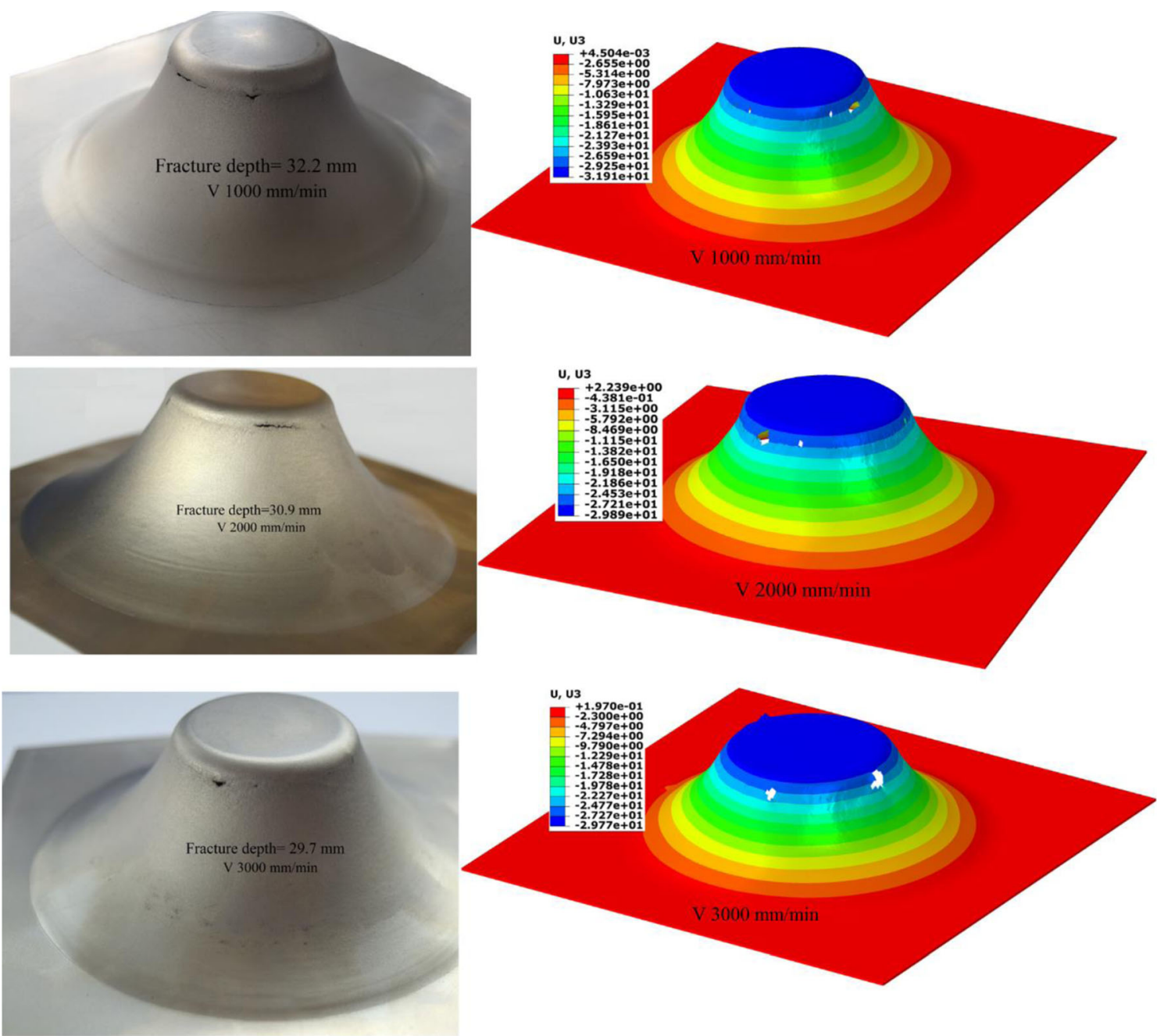

Fig. 18 Simulated results of fracture depth (Z-displacement) from the modified GTN model with stress triaxiality in comparison to the actual experiment of the pure Ti grade 1 hyperbolic cone shape with different feed rates 

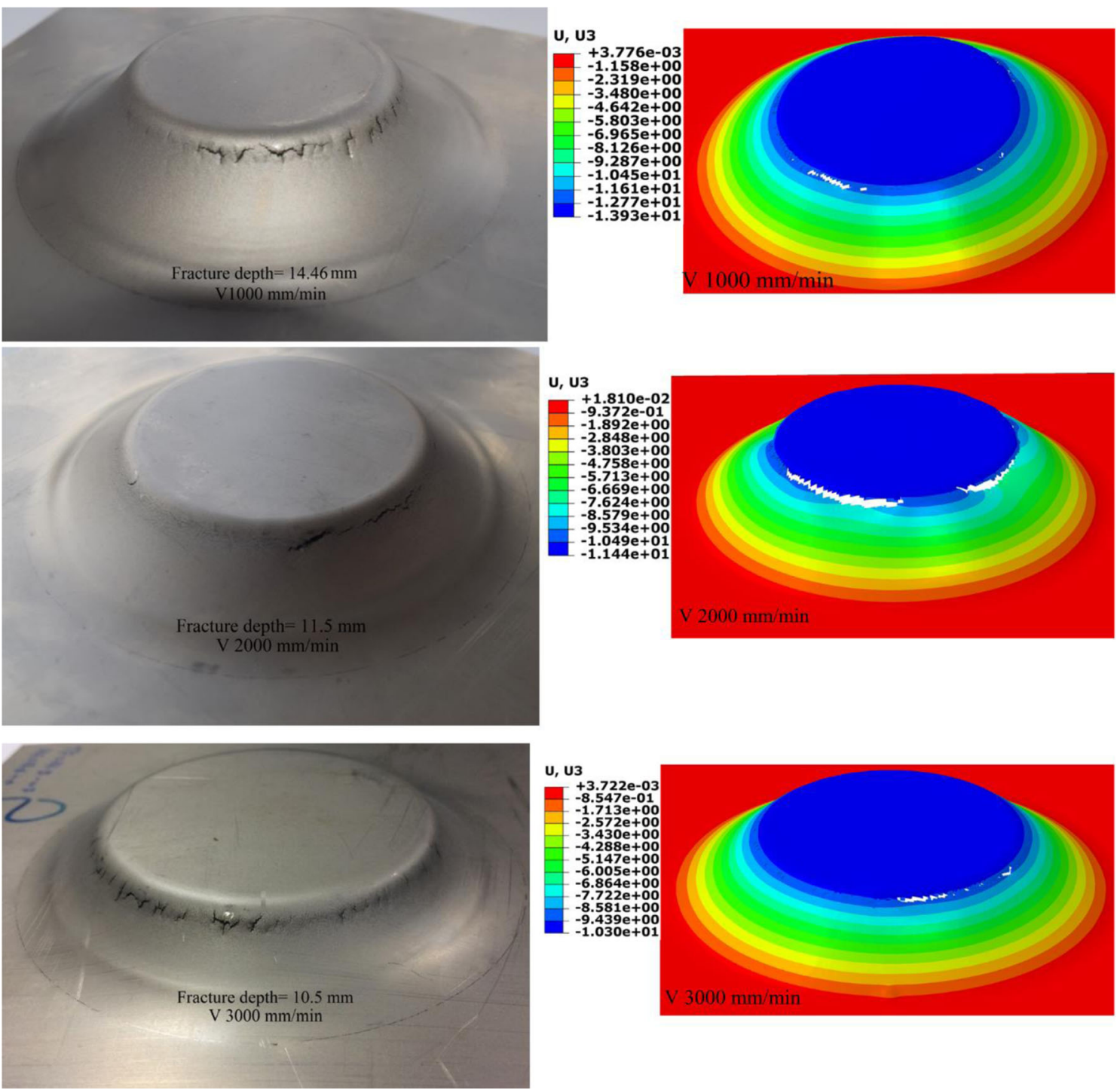

Fig. 19 Simulated results of fracture depth (Z-displacement) from the modified GTN model with stress triaxiality in comparison to the actual experiment of the pure Ti grade 2 hyperbolic cone shape with different feed rates

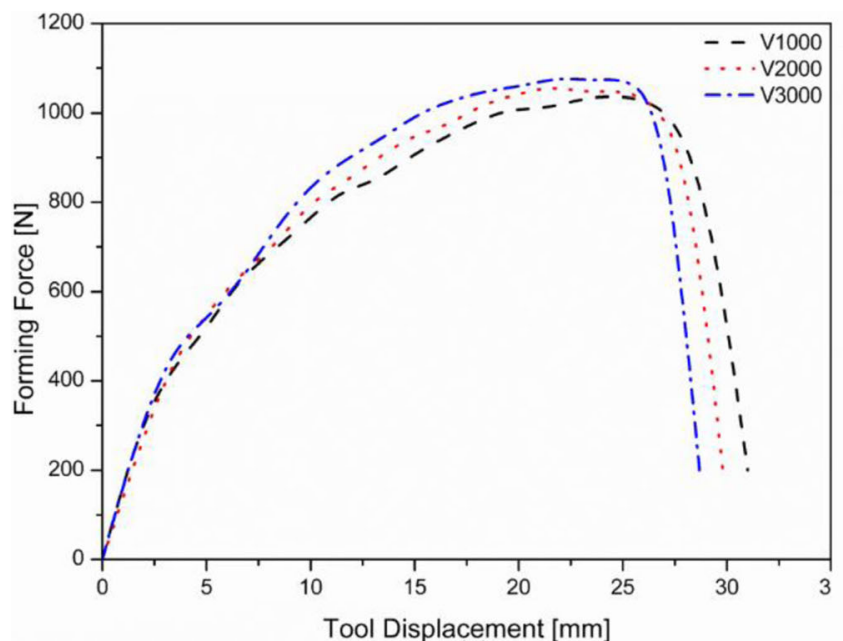

(a)

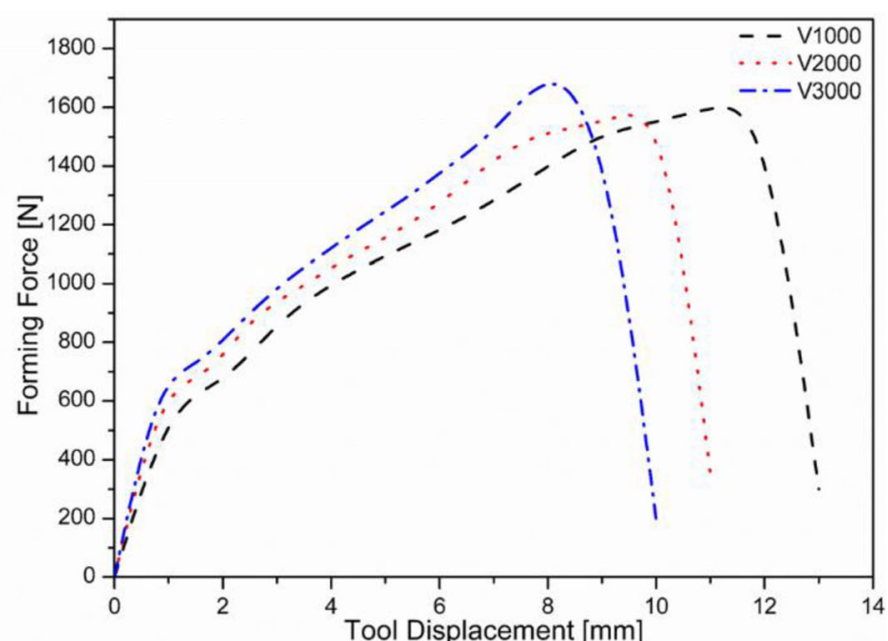

(b)

Fig. 20 Comparison of vertical forming load with different feed rates (V): a pure Ti grade 1 and (b) pure Ti grade 2 


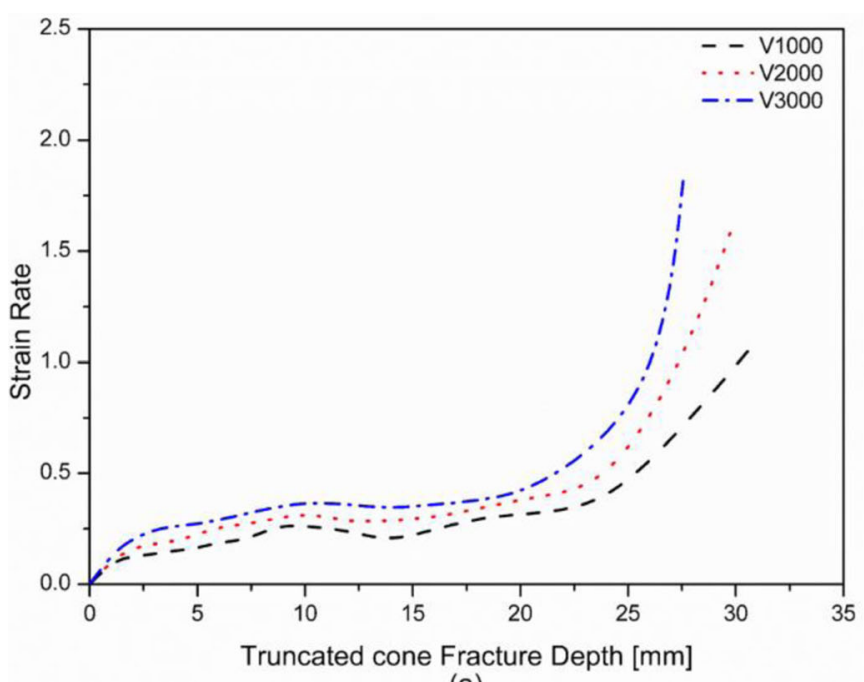

(a)

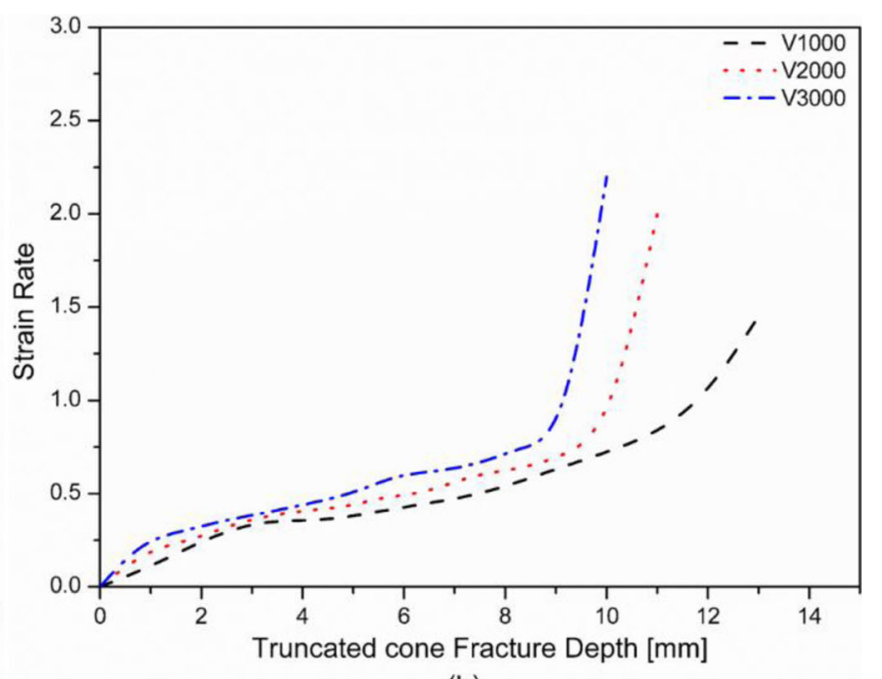

(b)

Fig. 21 Strain rate distribution with different feed rates (V): a pure Ti grade 1 and (b) pure Ti grade 2

increase stretching in the wall of the ISF part, which leads to increase the stress distribution with a low level of major strain, as well as enhancing the growth of initial voids in the pure Ti matrix to reach the fracture value early.

\section{Effect of feed rate}

Three feed rates were employed, i.e. 1000, 2000 and $3000 \mathrm{~mm} / \mathrm{min}$ (Experiment Nos. 1, 4 and 5, respectively) to examine the influence of feed rate on the formability and fracture depth of grade 1 and 2 pure Ti of a hyperbolic truncated cone with a non-rotating tool. The experimental and FE data on the maximum wall angle and fracture depth of grade 1 and 2 pure Ti are reported in Table 7. From the table, it is evident that improved formability can be achieved with a low feed rate for both types of pure Ti. $2.73^{\circ}$ of experimental wall angle can be earned with grade 1 pure Ti when the feed rate is changed from $3000 \mathrm{~mm} / \mathrm{min}$ to $1000 \mathrm{~mm} / \mathrm{min}$, while $6.1^{\circ}$ is earned with grade 2 pure Ti.

The predicted fracture depth of the ISF process under different feed rates was validated by the experimental depth, as shown in Table 7 and Figs. 18 and 19. It is clear that the fracture depth shows a good correlation between simulations using Abaqus/explicit with the stress triaxiality modified GTN model and the experimental measurements.

Figure 20 shows the effect of feed rate on the vertical forming force. The figure reveals that the ISF force increases with increasing feed rate for both grades of Pure Ti. This is attributed to higher strain rate levels; when the feed rate increases, the strain rate increases, as shown in Fig. 21. It is wellknown that high strain has a significant effect on fracture occurrence; when the strain rate increases, the fracture occurs

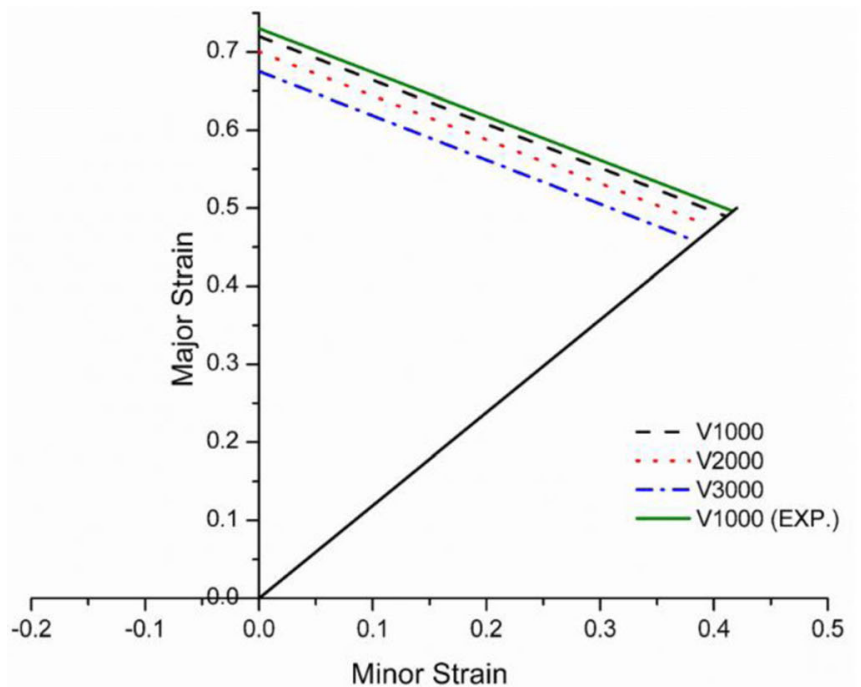

(a)

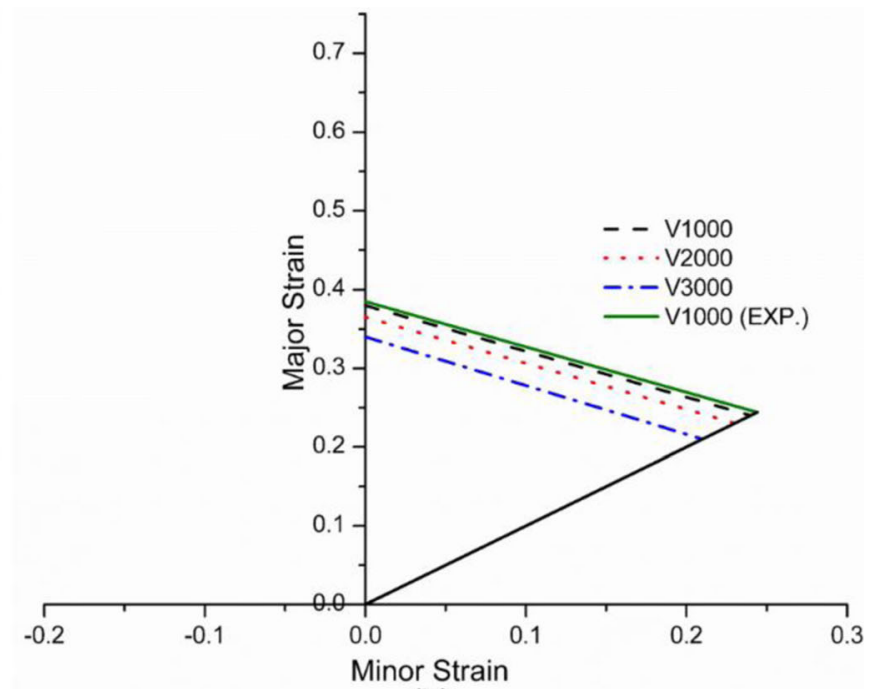

(b)

Fig. 22 FFL $\mathrm{s}$ with different feed rates (V): a pure Ti grade 1 and (b) pure Ti grade 2 


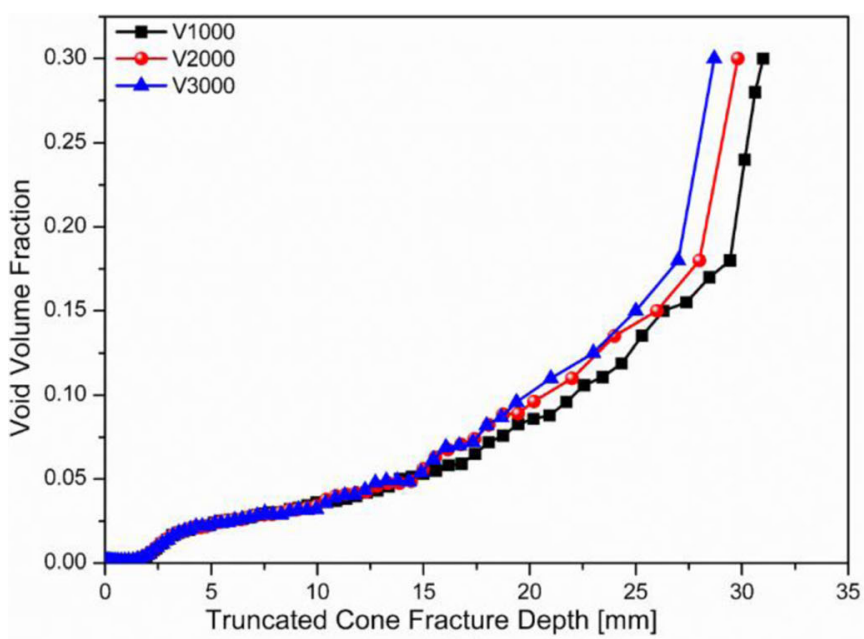

(a)

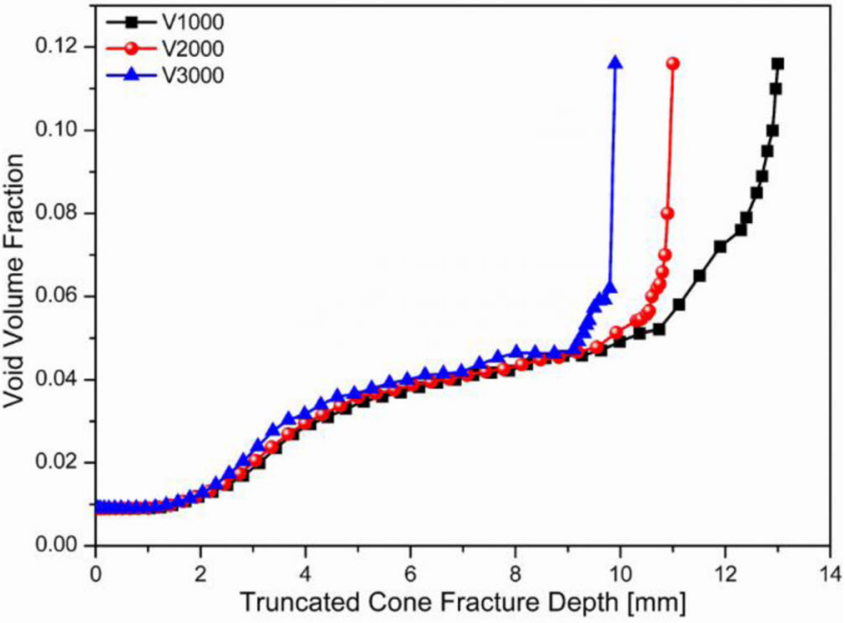

(b)

Fig. 23 Distribution of the void volume fraction obtained by numerical simulation of the ISF process with different feed rates (V): a pure Ti grade 1 and (b) pure Ti grade 2

early. From the mechanical properties of grade 1 and 2 pure $\mathrm{Ti}$ (Fig. 1), it can be seen that the pure Ti grade 1 is more ductile than grade 2. However, Table 7 and Fig. 21 show the grade 2 pure titanium more sensitive to the feed rate, meaning that the strain rate has a small effect in high ductility materials.

With a high strain rate, the fracture is accelerated and the level of strain at fracture is reduced. Therefore, the FFL is enhanced with a low feed rate, as shown in Fig. 22. The value of major strain at fracture of grade 1 pure Ti changes from 0.675 to 0.72 when the feed rate changes from $3000 \mathrm{~mm} / \mathrm{min}$ to $1000 \mathrm{~mm} / \mathrm{min}$, while the FFL of grade 2 pure Ti changes from 0.34 to 0.38 . The level of void volume fraction increases with the feed rate, as shown in Fig. 23; this is because with a high strain rate, the forming force increases and this can help the initial voids to enlarge, leading to an increase in the value of the void volume fraction in the transition zone between the contact and non-contact zones, and fracture occurs when the void volume fraction reaches the fracture value. Earlier studies have been reported that both size of void and strength properties increase with the increase of the strain rate [39, 40].

The predicted thickness was compared with that of the experiment to illustrate the effect of feed rate on thickness distribution, as shown in Fig. 24. There is a good correlation in the thickness distribution of the hyperbolic truncated cone between the GTN model with the consideration of stress triaxiality and the measured thickness results from ISF experiments. It is shown that relatively high levels of thinning can be achieved with a low feed rate $(1000 \mathrm{~mm} / \mathrm{min})$ due to the fact that a high wall angle can be achieved with a low feed rate.

In summary, it can be concluded that the low feed rate to some degree postpones the fracture occurrence in both types pf pure $\mathrm{Ti}$, although its effect is greater in pure Ti grade 2 . It

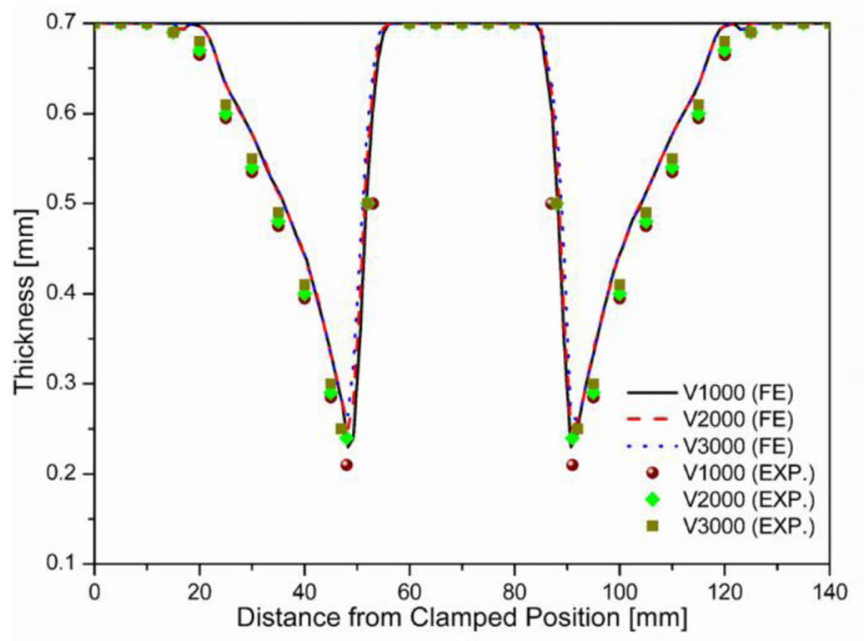

(a)

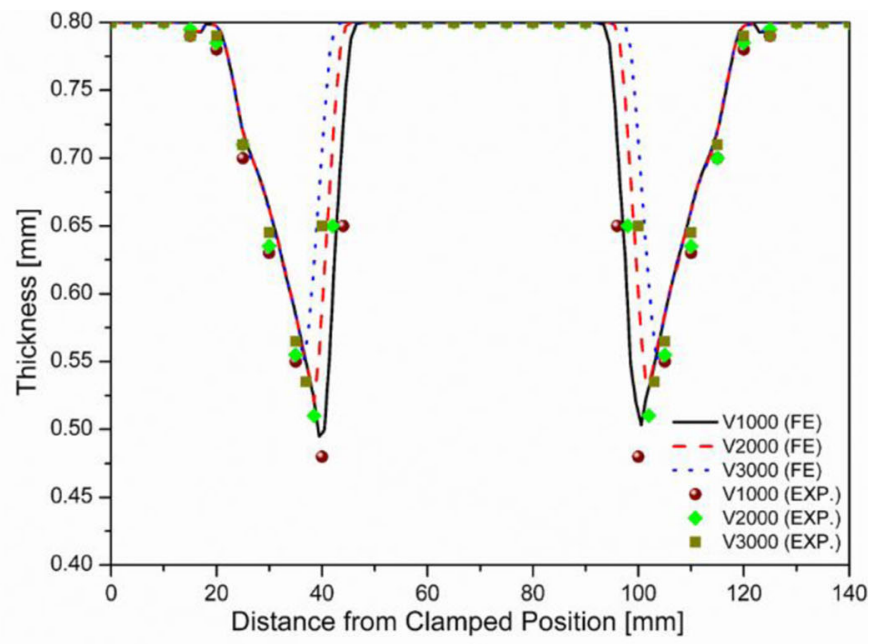

(b)

Fig. 24 Thickness distribution with different feed rates (V): a pure Ti grade 1 and (b) pure Ti grade 2 
Table 8 Effect of tool diameter on the formability and fracture of ISF grade 1 and 2 pure Ti

\begin{tabular}{|c|c|c|c|c|c|c|c|c|}
\hline \multirow[t]{3}{*}{ tool diameter $[\mathrm{mm}]$} & \multicolumn{4}{|c|}{ Pure Ti grade 1} & \multicolumn{4}{|c|}{ Pure Ti grade 2} \\
\hline & \multicolumn{2}{|c|}{ Fracture depth $[\mathrm{mm}]$} & \multicolumn{2}{|c|}{ Fracture angle $\left[{ }^{\circ}\right]$} & \multicolumn{2}{|c|}{ Fracture depth $[\mathrm{mm}]$} & \multicolumn{2}{|c|}{ Fracture angle $\left[^{\circ}\right.$} \\
\hline & $\mathrm{FE}$ & EXP. & $\mathrm{FE}$ & EXP. & $\mathrm{FE}$ & EXP. & $\mathrm{FE}$ & EXP. \\
\hline 8 & 34.5 & 35.1 & 73 & 73.96 & 15 & 15.5 & 49.55 & 51.2 \\
\hline 10 & 31 & 32.2 & 69.45 & 70.83 & 13 & 14.46 & 47.74 & 49.83 \\
\hline 15 & 28.5 & 29.86 & 66.7 & 68.28 & 9.3 & 10 & 40.5 & 43.55 \\
\hline
\end{tabular}

seems that stabilising effects are present with a low feed rate (low strain rate), which delays damage evolution, as compared to the ISF test conditions of high feed rate.

\section{Effect of tool diameter}

Three sizes of hemispherical head tool, 8, 10 and $15 \mathrm{~mm}$ (Experiment Nos. 6,1 and 7) were utilized to evaluate the effect of tool diameter on the formability and fracture depth of pure Ti grade 1 and 2 . Table 8 summarizes the values of fracture depth and the maximum wall angle of the pure $\mathrm{Ti}$ grade 1 and 2 hyperbolic truncated cone. It is clear from the table that formability and fracture are enhanced with small tool diameter. Therefore, the experimental wall angle of grade 1 pure Ti increases by $5.68^{\circ}$ when the tool diameter is changed from $15 \mathrm{~mm}$ to $8 \mathrm{~mm}$, while $7.65^{\circ}$ is earned with grade 2 pure
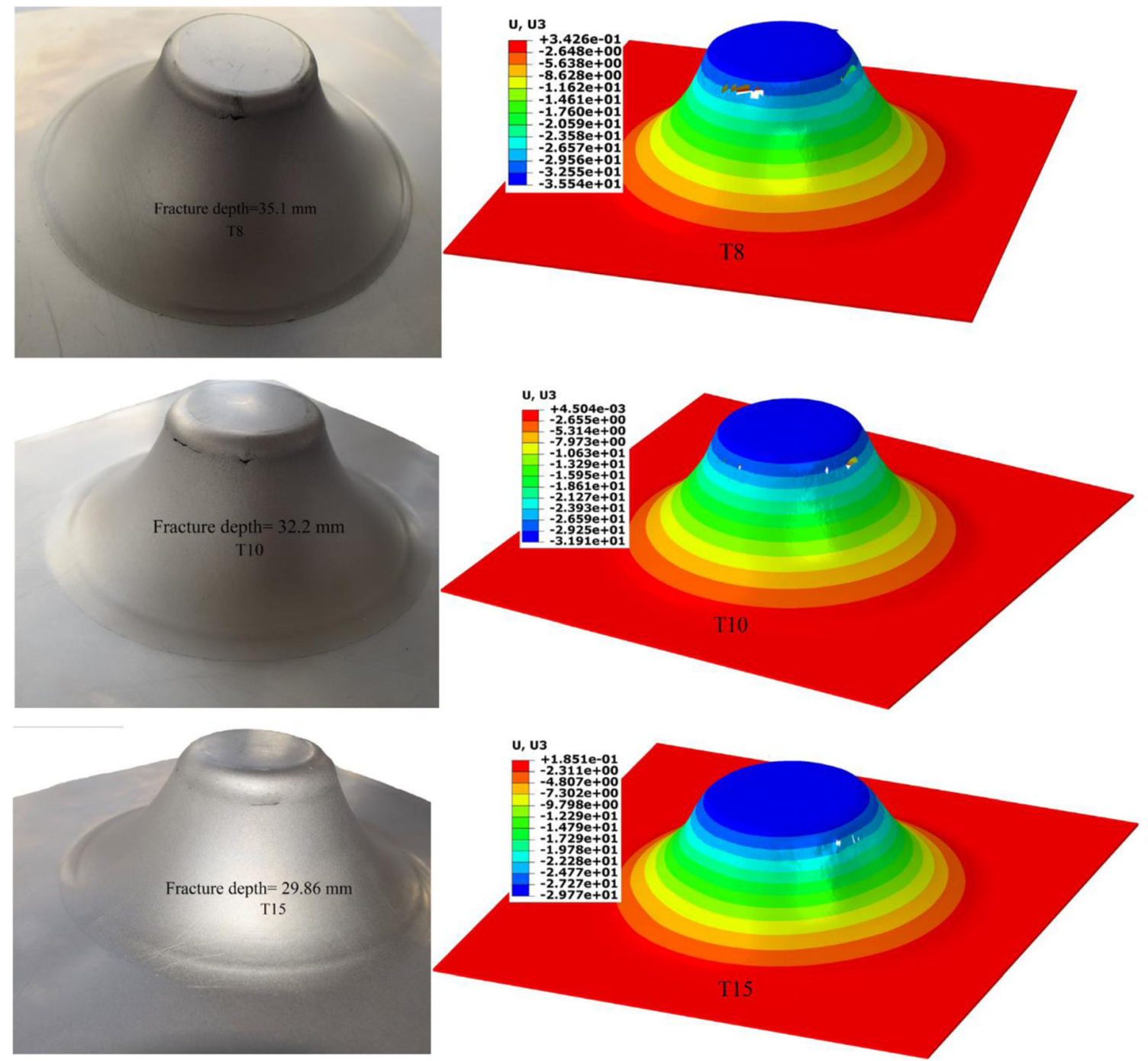

Fig. 25 Simulated results of fracture depth (Z-displacement) from the modified GTN model with stress triaxiality in comparison with the actual experiment of the pure Ti grade 1 hyperbolic cone shape with different tool diameters 
Ti.The fracture results show that the grade 2 pure Ti is more sensitive to change tool diameter than grade 1 pure Ti.

The depths of the ISF truncated cone by predicted Abaqus (stress triaxiality modified GTN model) with different tool diameters are consistent with one of the actual experiments for both pure Ti types, as shown in Table 8 and Figs. 25 and 26.

Figure 27 illustrates the effect of tool diameter on the vertical forming force of the ISF process. It is seen from the figure that the forming load varies with different tool diameters and increases with larger tool diameters for both types of pure Ti; this is due to a bigger contact zone being created with a large tool diameter and an increase in the forming force when the contact zone is bigger. With a small tool diameter, a highly concentrated zone of deformation is generated in the tool/ sheet contact zone and high strain is obtained, leading to improved formability; as shown in Fig. 28, the value of major strain is $0.75,0.72$ and 0.67 for pure Ti grade 1 , and $0.4,0.38$ and 0.34 for pure Ti grade 2 with tool diameters of 8,10 and $15 \mathrm{~mm}$, respectively.

The growth of voids increases under high tensile forming force, resulting in accelerated fracture occurrence, as shown in Fig. 29; with a large tool diameter, the void volume fraction reaches the fracture value earlier. The predicted thinning was compared with the experiment to investigate the effect of tool diameter on thickness distribution and to validate the applicability of the stress triaxiality modified GTN model to predict the accurate thickness at fracture. Figure 30 shows the thickness distribution of pure $\mathrm{Ti}$ grade 1 and 2 with different tool diameters. It is noted that the significant thinning occurs with a small tool diameter due to a higher wall angle being achieved with a small tool diameter; that means that the wall angle has a significant
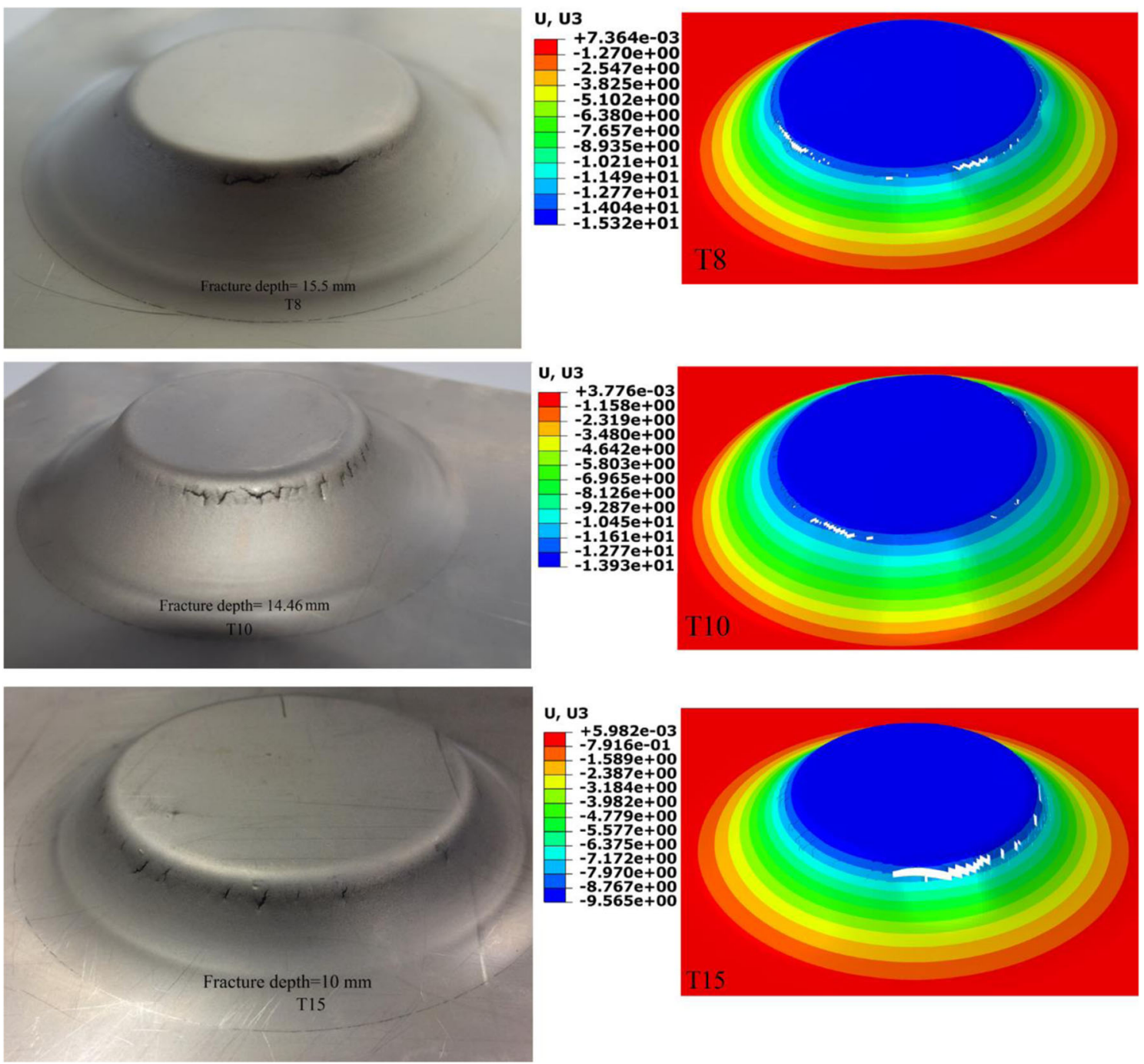

Fig. 26 Simulated results of fracture depth (Z-displacement) from the modified GTN model with stress triaxiality in comparison with the actual experiment of the pure Ti grade 2 hyperbolic cone shape with different tool diameters 


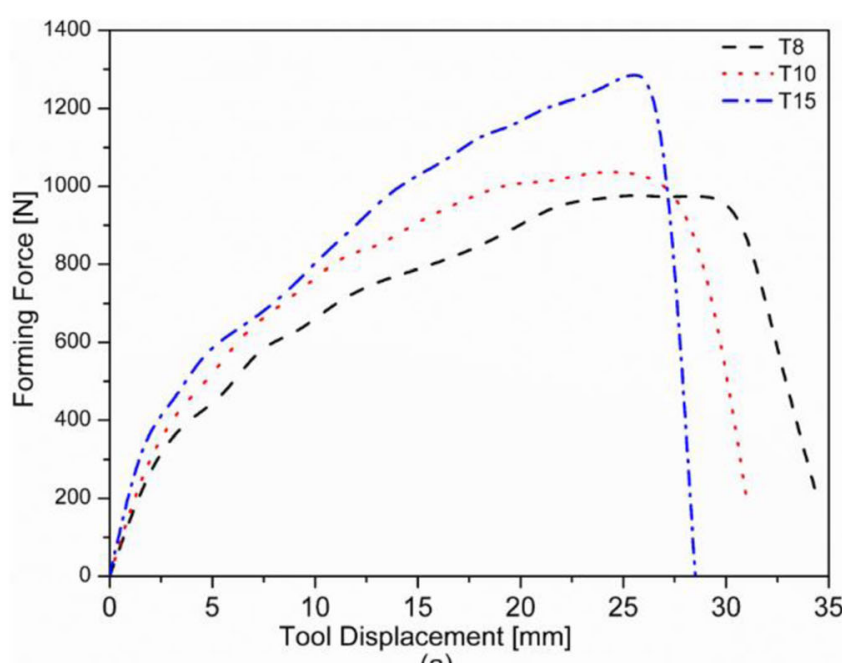

(a)

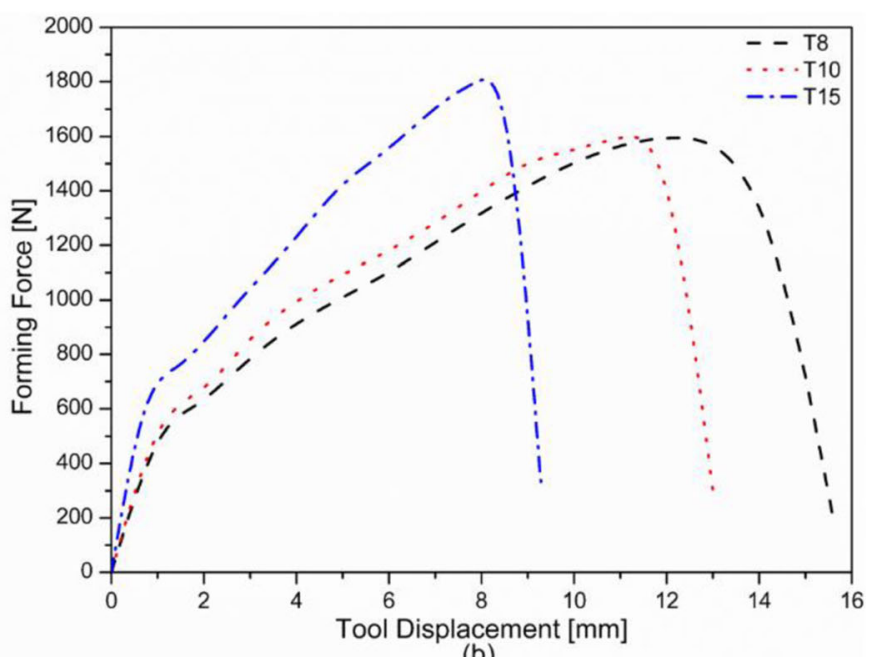

(b)

Fig. 27 Comparison of vertical forming load with different tool diameters (T): a pure Ti grade 1 and (b) pure Ti grade 2

influence on the maximum thinning value in the ISF process. The thickness results showed a good correlation between the prediction and experimental data. As a result, with a small tool diameter fracture occurrence is delayed and formability is enhanced.

The SPIF simulated results by stress triaxiality-modified GTN damage model correlate well with the actual experiments with a low percentage of differences as shown in Figs. 11, 12, 18, 19, 25 and 26. These differences can be accounted for by possible errors in both analyses and experiments. The possible errors may be due to the lack of detail information of such as friction conditions and the effect of anisotropy of the Ti materials which is neglected in this study. Although the SPIF experiments were set up and carried out consistently, there may be still a degree of variation under SPIF conditions.

\section{Conclusions}

A parametric investigation was undertaken in order to provide a better understanding of the relationship between three key ISF parameters, namely the step-down, feed rate and tool diameter, and the formability and fracture occurrence of grade 1 and 2 pure Ti using experimental testing and $\mathrm{FE}$ analysis incorporating the stress triaxiality modified GTN damage model. In addition, the degree of sensitivity of material types to the ISF parameters was explained. The following conclusions may be drawn from the above investigation:

1) The comparison between the experimental results and FE analysis using the stress triaxiality modified GTN damage model highlighted its accuracy in predicting fracture

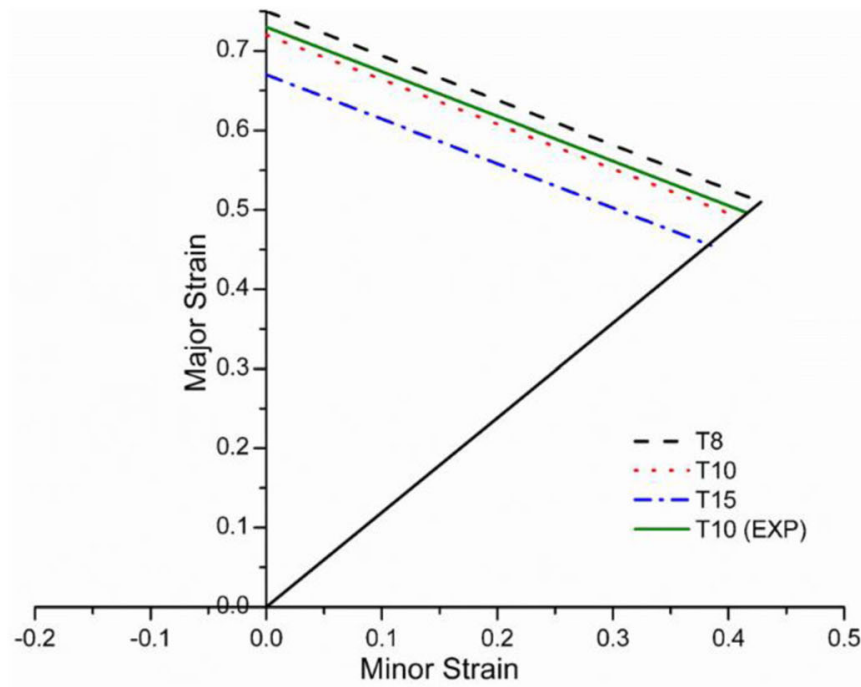

(a)

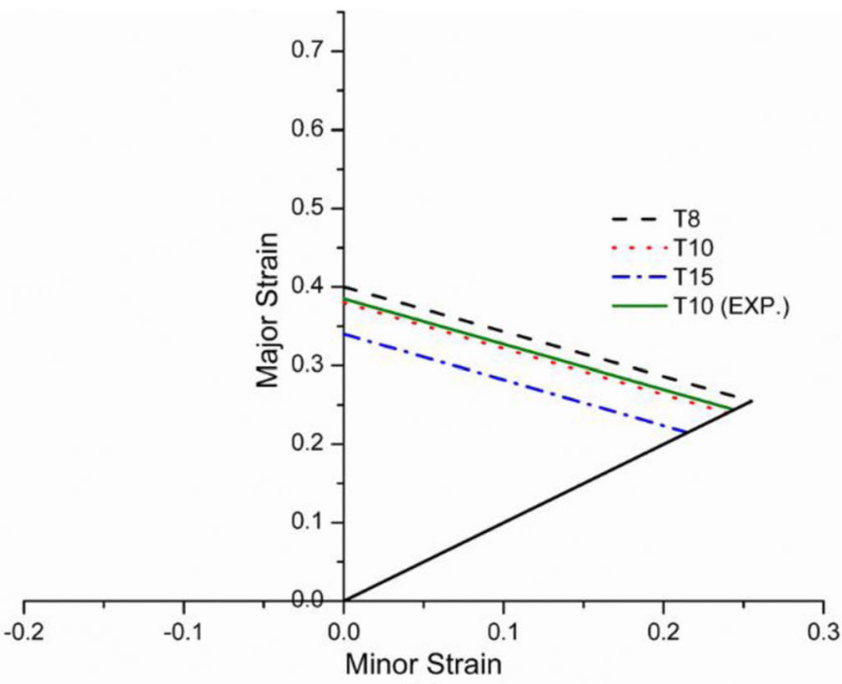

(b)

Fig. 28 FFLs with different tool diameters (T): a pure Ti grade 1 and (b) pure Ti grade 2 


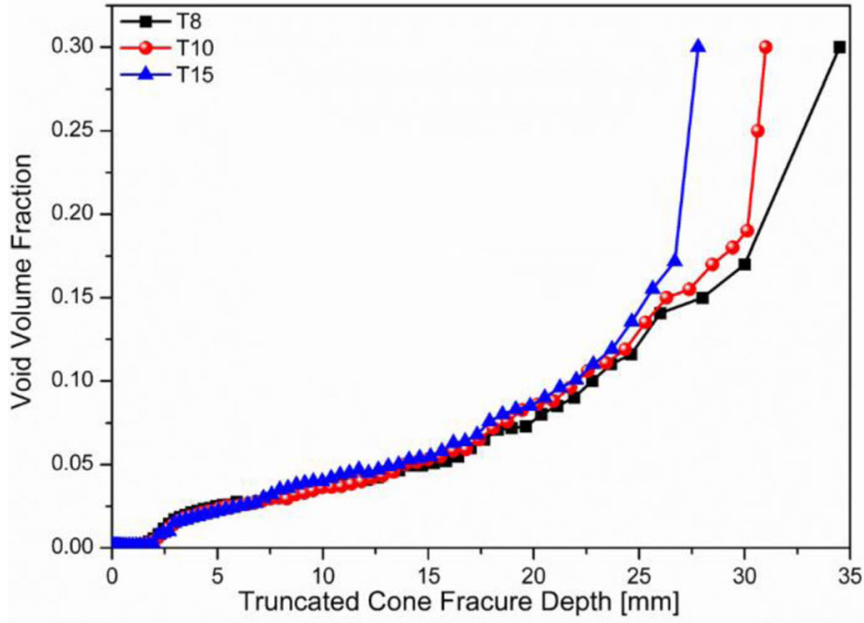

(a)

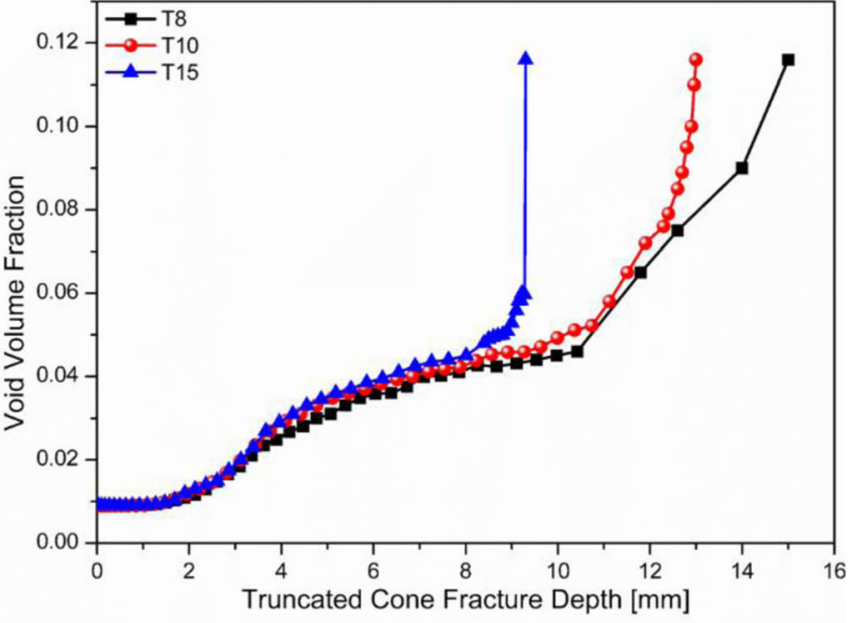

(b)

Fig. 29 Distribution of the void volume fraction obtained by numerical simulation of the ISF process with different tool diameters (T): a pure Ti grade 1 and (b) pure Ti grade 2

occurrence in the ISF of truncated hyperbolic cone and pyramidal shapes with different forming parameters.

2) The step-down, feed rate and tool diameter have different degrees of effect on the formability and fracture occurrence of the ISF process, and the grade 2 pure $\mathrm{Ti}$ is more sensitive to forming parameters than grade 1 pure Ti. The maximum wall angle of the grade 1 pure Ti hyperbolic truncated cone increases by $0.85^{\circ}, 2.73^{\circ}$ and $5.68^{\circ}$ when the step-down is changed from $0.6 \mathrm{~mm}$ to $0.4 \mathrm{~mm}$ to $0.2 \mathrm{~mm}$; the feed rate changes from $3000 \mathrm{~mm} / \mathrm{min}$ to $2000 \mathrm{~mm} / \mathrm{min}$ to $1000 \mathrm{~mm} / \mathrm{min}$ and the tool diameter changes from $15 \mathrm{~mm}$ to $10 \mathrm{~mm}$ to $8 \mathrm{~mm}$, respectively, whereas the increase in the maximum wall angle of grade 2 pure Ti is $5^{\circ}, 6.1^{\circ}$ and $7.65^{\circ}$ with the same changes of the ISF parameters.

3) With the increased step-down, feed rate and tool diameter, the vertical forming force increases accordingly with both

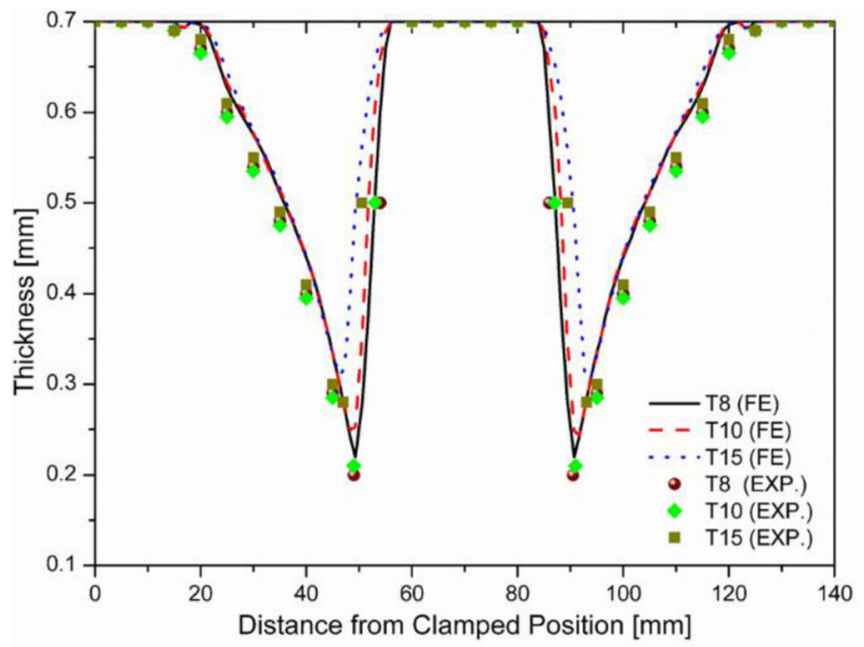

(a) types of pure Ti. The increase in the forming force with increased step-down and tool diameter can be attributed to the increase of material to deform and to the increased contact area between the tool and the sheet, respectively. Whilst the increases in feed rate result in a degree of strain rate hardening effect in ISF.

4) The level of major strain at fracture decreases with increased forming parameters (step-down, feed rate and tool diameter) for both types of pure Ti.

5) The increases in the step-down, feed rate and tool diameter can help to nucleate new voids in a pure Ti matrix and accelerate the growth of initial voids, leading to an increase in the value of the void volume fraction in the transition zone between the contact and non-contact zones; in addition, fracture occurs when the void volume fraction reaches a certain value $(0.305$ in pure Ti Grade 1 and 0.116 in pure Ti grade 2 ).

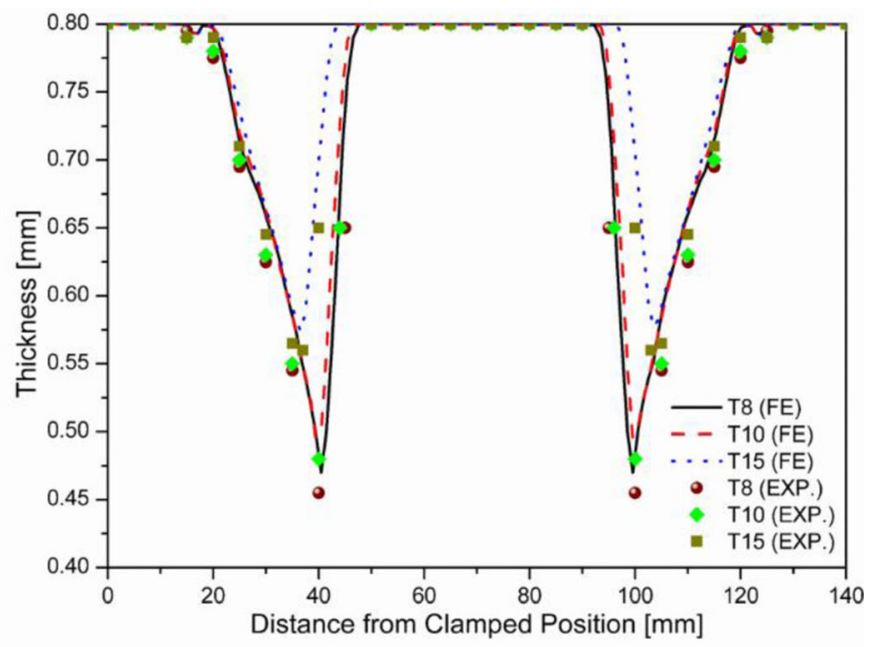

(b)

Fig. 30 Thickness distribution with different tool diameters (T): a pure Ti grade 1 and (b) pure Ti grade 2 
6) More thinning can be seen in the wall of the hyperbolic truncated cone in the transition region between the contact and non-contact zone when the step-down, feed rate and tool diameter decrease due to a higher wall angle being achieved when these parameters are decreased.

7) Increase in feed rate and hence strain rate speeds up fracture occurrence in the ISF process.

8) In this study, the GTN damage model was developed to predict fracture in the ISF process based on the assumption that the material behaviour of the sheet was isotropic. The GTN model can be extended to include the effects of kinematic hardening and anisotropy of the Ti material to study the effect of hardening behaviour and material anisotropy on the location and depth of fracture in ISF.

Acknowledgements The first author gratefully acknowledges the scholarship support provided by the Iraqi Ministry of Higher Education and Scientific Research (IMHESR) Ref. no. 4720. This work was supported by the Engineering and Physical Science Research Council [grant number EP/L02084X/1] and the International Research Staff Exchange Scheme [IRSES, MatProFuture project, 318,968] within the 7th European Community Framework Programme (FP7). The authors thank the Nanoscale and Microscale Research Centre (nmRC) at Nottingham for providing access to instrumentation.

\section{Compliance with ethical standards}

Conflict of interest The authors declare that they have no conflict of interest.

Open Access This article is distributed under the terms of the Creative Commons Attribution 4.0 International License (http:// creativecommons.org/licenses/by/4.0/), which permits unrestricted use, distribution, and reproduction in any medium, provided you give appropriate credit to the original author(s) and the source, provide a link to the Creative Commons license, and indicate if changes were made.

Publisher's Note Springer Nature remains neutral with regard to jurisdictional claims in published maps and institutional affiliations.

\section{References}

1. Gatea S, Ou H, McCartney G (2016) Review on the influence of process parameters in incremental sheet forming. The International Journal of Advanced Manufacturing Technology p. 1-21

2. Han F, Mo J-h (2008) Numerical simulation and experimental investigation of incremental sheet forming process. J Cent S Univ Technol 15(5):581-587

3. Jun-chao L, Chong L, Zhou T-g (2012) Thickness distribution and mechanical property of sheet metal incremental forming based on numerical simulation. Trans Nonferrous Metals Soc China 22:s54 s60

4. Ambrogio G, Filice L, Fratini L, Micari F (2004) Process mechanics analysis in single point incremental forming. In AIP Conference Proceedings. AIP

5. Duflou J, Tunçkol Y, Szekeres A, Vanherck P (2007) Experimental study on force measurements for single point incremental forming. J Mater Process Technol 189(1):65-72
6. Ham M, Jeswiet J (2006) Single point incremental forming and the forming criteria for AA3003. CIRP Ann Manuf Technol 55(1):241244

7. Bhattacharya A, Maneesh K, Venkata Reddy N, Cao J (2011) Formability and surface finish studies in single point incremental forming. J Manuf Sci Eng 133(6):061020

8. Decultot N, Robert L, Velay V, Bernhart G (2010) Single point incremental sheet forming investigated by in-process $3 \mathrm{D}$ digital image correlation. EPJ Web of Conferences 6:11001

9. Fritzen D, Daleffe A, Castelan J, Schaeffer L (2013) Brass 70/30 and incremental sheet forming process. Key Eng Mater 554:14191431

10. Kim YS, Lee HJ, Park JG, Nguyen DT (2010) Finite element method study of incremental sheet forming for complex shape and its improvement. Proc Inst Mech Eng B J Eng Manuf 224(6):913-924

11. Ham M, Jeswiet J (2007) Forming limit curves in single point incremental forming. CIRP Ann Manuf Technol 56(1):277-280

12. Silva MB, Nielsen PS, Bay N, Martins PAF (2011) Failure mechanisms in single-point incremental forming of metals. Int $\mathrm{J}$ Adv Manuf Technol 56(9-12):893-903

13. Centeno G, Bagudanch I, Martínez-Donaire AJ, García-Romeu ML, Vallellano C (2014) Critical analysis of necking and fracture limit strains and forming forces in single-point incremental forming. Mater Des 63:20-29

14. Buffa G, Campanella D, Fratini L (2013) On the improvement of material formability in SPIF operation through tool stirring action. Int J Adv Manuf Technol 66(9-12):1343-1351

15. Kim Y, Park J (2002) Effect of process parameters on formability in incremental forming of sheet metal. J Mater Process Technol 130: $42-46$

16. Hussain G, Gao L, Hayat N, Cui Z, Pang Y, Dar N (2008) Tool and lubrication for negative incremental forming of a commercially pure titanium sheet. J Mater Process Technol 203(1):193-201

17. Hussain G, Gao L, Zhang Z (2008) Formability evaluation of a pure titanium sheet in the cold incremental forming process. Int $\mathrm{J}$ Adv Manuf Technol 37(9):920-926

18. Attanasio A, Ceretti E, Giardini C, Mazzoni L (2008) Asymmetric two points incremental forming: improving surface quality and geometric accuracy by tool path optimization. J Mater Process Technol 197(1):59-67

19. Hagan E, Jeswiet J (2004) Analysis of surface roughness for parts formed by computer numerical controlled incremental forming. $\mathrm{J}$ Eng Manuf 218(Part B):1307-1312

20. Oleksik V, Pascu A, Deac C, Fleacă R, Bologa O, Racz G (2010) Experimental study on the surface quality of the medical implants obtained by single point incremental forming. Int $\mathrm{J}$ Mater Form 3(S1):935-938

21. Silva PJ, Leodido LM, Silva CRM (2013) Analysis of incremental sheet forming parameters and tools aimed at rapid prototyping. In Key Engineering Materials. Trans Tech Publ

22. Ai S, Lu B, Chen J, Long H, Ou H (2017) Evaluation of deformation stability and fracture mechanism in incremental sheet forming. Int J Mech Sci 124:174-184

23. Fang Y, Lu B, Chen J, Xu DK, Ou H (2014) Analytical and experimental investigations on deformation mechanism and fracture behavior in single point incremental forming. J Mater Process Technol 214(8):1503-1515

24. Gatea S, Ou H, Lu B, McCartney G (2017) Modelling of ductile fracture in single point incremental forming using a modified GTN model. Eng Fract Mech 186

25. Jackson K, Allwood J (2009) The mechanics of incremental sheet forming. J Mater Process Technol 209(3):1158-1174

26. Malhotra R, Xue L, Cao J, Belytschko T (2011) Identification of deformation mechanisms responsible for failure in incremental forming using a damage based fracture model. AIP Conf Proc 1383(1):469-476 
27. Malhotra R, Xue L, Belytschko T, Cao J (2012) Mechanics of fracture in single point incremental forming. J Mater Process Technol 212(7):1573-1590

28. Martins PAF, Bay N, Skjoedt M, Silva MB (2008) Theory of single point incremental forming. CIRP Ann Manuf Technol 57(1):247252

29. Silva MB, Skjoedt M, Martins PAF, Bay N (2008) Revisiting the fundamentals of single point incremental forming by means of membrane analysis. Int J Mach Tool Manu 48(1):73-83

30. Gurson AL (1977) Continuum theory of ductile rupture by void nucleation and growth: part I-yield criteria and flow rules for porous ductile media. J Eng Mater Technol 99(1):2-15

31. Tvergaard V, Needleman A (1984) Analysis of the cup-cone fracture in a round tensile bar. Acta Metall 32(1):157-169

32. Gatea S, Xu D, Ou H, McCartney G (2017) Evaluation of formability and fracture of pure titanium in incremental sheet forming. The International Journal of Advanced Manufacturing Technology p. $1-17$

33. Tvergaard V (1982) Influence of void nucleation on ductile shear fracture at a free surface. J Mech Phys Solids 30(6):399-425
34. Nahshon K, Hutchinson J (2008) Modification of the Gurson model for shear failure. Eur J Mech A Solids 27(1):1-17

35. Nielsen KL, Tvergaard V (2010) Ductile shear failure or plug failure of spot welds modelled by modified Gurson model. Eng Fract Mech 77(7):1031-1047

36. Isik K, Silva MB, Tekkaya AE, Martins PAF (2014) Formability limits by fracture in sheet metal forming. J Mater Process Technol 214(8):1557-1565

37. Chen Z, Dong X (2009) The GTN damage model based on Hill'48 anisotropic yield criterion and its application in sheet metal forming. Comput Mater Sci 44(3):1013-1021

38. Kami A, Dariani BM, Vanini AS, Comsa DS, Banabic D (2015) Numerical determination of the forming limit curves of anisotropic sheet metals using GTN damage model. J Mater Process Technol 216:472-483

39. Bae D, Ghosh A (2002) Cavity growth during superplastic flow in an Al-Mg alloy: I. Experimental study. Acta Mater 50(5):993-1009

40. Das A, Sivaprasad S, Chakraborti P, Tarafder S (2008) Correspondence of fracture surface features with mechanical properties in 304LN stainless steel. Mater Sci Eng A 496(1):98-105 